\title{
Multiresonant Frequency Piezoelectric Energy Harvesters Integrated with High Sensitivity Piezoelectric Accelerometer for Bridge Health Monitoring Applications
}

\author{
Prathish Raaja Bhaskaran, ${ }^{1}$ Joseph Daniel Rathnam, ${ }^{1}$ \\ Sumangala Koilmani, ${ }^{2}$ and Kavitha Subramanian' \\ ${ }^{1}$ Department of Electronics and Instrumentation Engineering, NPMASS MEMS Design Centre, \\ Annamalai University, Annamalai Nagar 608002, India \\ ${ }^{2}$ Department of Civil and Structural Engineering, Annamalai University, Annamalai Nagar 608002, India \\ Correspondence should be addressed to Joseph Daniel Rathnam; josuma.au@gmail.com
}

Received 20 July 2016; Revised 18 October 2016; Accepted 24 October 2016; Published 29 January 2017

Academic Editor: Yong Liu

Copyright ( 2017 Prathish Raaja Bhaskaran et al. This is an open access article distributed under the Creative Commons Attribution License, which permits unrestricted use, distribution, and reproduction in any medium, provided the original work is properly cited.

\begin{abstract}
Wireless Structural Health Monitoring (WSHM) is a less expensive but efficient mode of health monitoring. However, it needs frequent change of batteries since remote WSHM consumes large power. The best scientific solution to this problem is to employ energy harvesters integrated along with the vibration sensors in the same substrate so that the battery is recharged by the energy harvested during vibrations caused by the passing vehicles in bridges. In this work, an attempt has been made to design an energy harvester and a micro accelerometer integrated chip. Civil structures have low natural frequencies and therefore low bandwidth design is adopted to maximize the harvested energy and accelerometer sensitivity. The other special feature of the proposed design is its ability to provide further increase in energy harvesting by the parallel operation of an array of energy harvesters with closely spaced natural frequencies. The studies show that the natural frequencies of the harvesters should be less than that of the structure in healthy condition. Simulation studies conducted on these devices show that it is possible to harvest a maximum power of $2.283 \mathrm{~mW} / \mathrm{g}$. The integrated micro accelerometer is also capable of giving a sensitivity of $27.67 \mathrm{~V} / \mathrm{g}$ with appreciable improvement in other performance indices.
\end{abstract}

\section{Introduction}

Structural Health Monitoring (SHM) of civil structures and machinery, dynamic qualification in the design of novel components, fault prediction in aerosystems, and the diagnosis of structural dynamic effects have been traditionally carried out by vibration measurement and subsequent analysis of the signal acquired through such measurements $[1,2]$. MEMS accelerometers have been used nowadays for SHM in the place of conventional accelerometers due to their smaller sizes and lower costs [3-6]. Accelerometers used in these applications can employ one of several methods such as capacitive, piezoresistive, and piezoelectric. In the recent past, wireless SHM has been the main focus of the people engaged in the design and development of SHM systems.
The wireless system should transmit the data received from various sensors implanted in the structure in a more efficient way at the cost of least power since frequent change of battery is to be avoided in remote SHM. In this context, new power sources beyond rechargeable batteries have become important topics for current and future stand-alone devices and systems. Energy harvesting from ambient sources like radio frequency (RF), solar, thermal, wind and hydroflow, vibration, and pressure energies for wireless sensor network applications has been the research focus in the past [7-9]. Khan and Iqbal presented a novel electromagnetic bridge energy harvester using traffic-induced bridge's vibrations and ambient wind [10]. A radio frequency (RF) powered far-field battery-less wireless sensor network is presented to overcome the limitation of battery in WSNs [11, 12]. Solar energy 
harvesting scheme using a solar panel, a lithium battery, and associate control circuit has also been reported [13, 14]. Maruccio et al. propose to harvest ambient-induced vibrations of bridge structures using a new class of piezoelectric textiles using arrays of electrospun piezoelectric nanofibers [15]. Considering the fact that the vibration energy induced by the passing vehicles can be a useful source for energy harvesting, serious research efforts have been directed to design piezoelectric energy harvesters for wireless systems used in bridge health monitoring [8,16-20]. These studies indicate that vibration energy induced in the bridges is a reliable ambient energy source compared to other possible sources. But it is still not a reality wherein an energy harvester has been designed to harvest the power required by a wireless sensor node through the vibration energy generated by the passing vehicles.

Different configurations of energy transducers have been used to transform the kinetic vibration energy into electricity, among which the singled of mechanical system including its beam-type variation is one of the most popular [21]. In such cantilever beam based energy harvesters, deflection of the beams due to vibration induced by the ambient sources results in mechanical stress and a voltage is induced due to piezoelectric effect if the beam is made up of piezoelectric material [22]. Although cantilever piezoelectric power generator has many drawbacks such as weak mechanical strength, low piezoelectric voltage coefficient, limited maximum displacement due to restricted maximum applied force, and shortened life time fatigue caused by bending, it cannot stop people's interest in it because of its high strain and high power output even under lower acceleration amplitudes, which is typically the case in the signals picked from ambient vibrations in civil structures. Until now, cantilever structure for piezoelectric power generation has been extensively studied. The cantilever transducer has different configurations such as bimorph, unimorph, and rainbow [23]. Several techniques have been attempted to increase the harvester efficiency and one such approach is folding equally and then splitting a given dimension of piezoelectric material with the predefined dimensions so that the conversion of energy is more efficient by reducing the mechanical damping of the piezoelectric materials during the vibration [24]. Bridges are low frequency structures and therefore the vibrations induced in them too. It is well known that the magnitude of voltage induced in piezoelectric accelerometer and energy harvester devices can be higher in low frequency devices. Hence, the authors intend to improve the energy harvesting by low frequency design in this work [25-27]. But downscaling helps not to improve energy conversion and therefore micro energy harvesters cannot produce huge electrical power. Scientists have used parallel operation of micro energy harvesters to improve energy conversion $[28,29]$. In this background, the present work aims at developing an energy harvesting scheme employing an array of multiresonant frequency piezoelectric harvesters in parallel operation to achieve adequate energy harvesting. The idea behind this implementation is that the natural frequency of the bridge structures falls when they undergo damage. Hence it is possible to improve the energy harvesting and ensure reliable data transmission definitely even under stressed condition of the bridge by incorporating energy harvesters with resonant frequencies lower than the natural frequency of the bridge in the healthy conditions. This arrangement ensures that the battery is recharged by the energy harvested during vibrations and hence there is no need for frequent change of batteries. Further, piezoelectric accelerometers and harvester are fabricated in a simple process sequence suitable for batch fabrication of both accelerometer and encapsulation. The single-chip accelerometer integrated with harvester array can be fitted into a flat package which is advantageous for SHM applications [30].

The other significant aspect of this research is the integration of piezoelectric accelerometer also in the same substrate so that each sensor node has its own voltage source required for its operation and sensing electronics in a single chip. The piezoelectric accelerometer, the second important focus of this paper, consists of two parts: a piezoelectric material beam and a seismic mass. During acceleration the seismic mass exerts a force on the piezoelectric material beam resulting in the generation of a charge due to the piezoelectric effect. Piezoelectric accelerometers have many desirable features, such as extremely low power consumption, high sensitivity, inherent temperature stability, compatibility with CMOS manufacturing process [31-33], high Q in the range of 80 to 100 , low damping, high output impedance, and wide operating temperature range (up to $300^{\circ} \mathrm{C}$ ) $[31,34$, 35]. Design and fabrication of micromachined piezoelectric accelerometers have been reported widely [21-24, 30-36]. Such an accelerometer will record translational and rotational inertial accelerations, as well as gravitational acceleration, as long as parts of these acceleration vectors are in line with the accelerometer's axis of sensitivity. The most important characteristics of an accelerometer are the sensitivity and the operating frequency range. The sensitivity is defined as the ratio between the electrical output (charge or voltage) and the mechanical input (force or acceleration); the band where the sensitivity remains practically unchanged defines the operating frequency range which is upper limited by the first resonance frequency of the device. For civil structural health monitoring applications, the accelerometers need to measure very low frequency signals (1 to $100 \mathrm{~Hz}$ ) of very small acceleration signals $(<40 \mathrm{mg})$. High sensitivity and low noise floor can be achieved by just designing the accelerometers for low bandwidth since the sensitivity is inversely proportional to the square of the natural frequency. This would be explained in later section. Based on this principle, low frequency piezoresistive and capacitive micro accelerometers exclusively meant for structural health monitoring applications have been designed and reported by the authors in their previous reports [25-27]. In this work, the authors intend to generate the design guidelines for design and manufacture of piezoelectric accelerometers for structural health monitoring. Active materials with larger piezoelectric constants, such as PZT, can widen the performance gap of piezoelectric accelerometers [34, 37-45]. ZnO has also been employed for the active piezoelectric film due to relatively simple and repeatable deposition using single-target RF sputtering, the ability to produce large-area films without pinholes, and proven compatibility with IC integration [46-48]. There 
are reports that describe piezoelectric accelerometers using other piezoelectric materials too [49-51]. A cantilever beam accelerometer or energy harvester with a mass at the free end can result in large sensitivity piezoelectric accelerometer and large power in piezoelectric energy harvester. But cantilever beam with a mass is difficult to realize using surface micromachining and hence the majority of reports are on simple cantilever beam. But the authors use in this work a Silicon-on-Insulator (SoI) wafer wherein a cantilever beam with sufficiently large mass can be easily realized with bulk micromachining.

Low frequency design of energy harvester and accelerometer, parallel operation of multiresonant frequency energy harvesters for improving performance, and integration of such high performance harvesters array and micro accelerometers in a single chip for wireless bridge monitoring application are the main theme of this research paper. Therefore, the authors first discuss the structure of the proposed integrated energy harvester and accelerometer microsystem in Section 2. The analysis of these energy harvesters and accelerometers needs a suitable analytical model and such a model is presented in Section 3. It also discusses the simulation environment used in this work to study and evaluate various energy harvester designs. Section 4 is devoted to designing and analyzing the effect of parallel operation of multiresonant frequency energy harvester for effectively improving the energy harvesting. The design of accelerometers and their performance evaluation are presented in Section 5. The fabrication of this energy harvester and accelerometer integrated chip is discussed in Section 6. The conclusions are summarized in Section 7.

\section{Structure of SHM Accelerometer with Integrated Energy Harvesters}

The present system of accelerometer and energy harvester array integrated in a single chip as diagrammed in Figure 1(a) uses unimorph cantilever beams consisting of a piezoelectric layer bonded to a nonpiezoelectric layer of the same length and width. Multiple energy harvesters are realized on the same substrate for maximizing the harvested energy. Parallel configuration of these harvesters is proposed to increase the energy harvested. In this work, $\mathrm{ZnO}$ is considered for piezoelectric material and bulk silicon makes substrate layer for the beam and mass. For analysis, it is assumed that the bonding between the two layers is perfect and the piezoelectric layer is poled along its thickness direction. The $x$-axis is along the length of the cantilever with $x=0$ located at the fixed end of the cantilever. The $z$-axis is along the thickness direction with $z=0$ at the interface between the $\mathrm{ZnO}$ and Si layers. The thickness of the nonpiezoelectric layer $(\mathrm{Si})$ and that of the piezoelectric layer $(\mathrm{ZnO})$ are denoted as $t_{S}$ and $t_{p}$, respectively. The length of the cantilever beam is denoted as $L_{b}$ and its width is $W_{b}$. The mass has a length of $L_{m}$, width of $W_{m}$, and height of $h_{m}$ as indicated in Figure 1(b). The position of the electrical neutral plane $\left(t_{n 1}\right)$ is shown in Figure 1(b) and $t_{n 1}$ depends on the thicknesses and Young's moduli of the $\mathrm{ZnO}$ and $\mathrm{Si}$ layers. The neutral plane is the zero-charge plane in the composite beam made up of piezoelectric and nonpiezoelectric layer.

The ambient vibration under measurement itself acts as the source of energy for energy conversion. For example, when this system is installed in a bridge, the vibration caused by the moving vehicles is measured to predict and diagnose the structural condition and the same vibration energy is converted into electrical energy by the harvester to charge the battery and provide the power required to transmit the picked up vibration signal to the remote receiver.

\section{Modeling of Unimorph Piezoelectric Cantilever Beams}

Successful design and implementation of piezoelectric accelerometers and piezoelectric energy harvesters need simple analytical models for easier analysis and design. Therefore, this section aims at developing the analytical models for the displacement, voltage induced, and charge sensitivity from the basic principles.

3.1. Displacement Analysis and Natural Frequency Model. The beam deflects upward or downward when the cantilever beam is subjected to acceleration in the $z$-direction, and therefore a voltage is induced due to the induced strain or stresses in the beam. Considering a concentrated force, $F$, acting perpendicularly to the cantilever mass surface as shown in Figure 1(b), the inverse of radius of curvature $(r)$ can be expressed as

$$
\frac{1}{r}=\frac{d^{2} h(x)}{d x^{2}}=\frac{M(x)}{W D_{1}}=-\frac{F}{w D_{1}}[L-x]
$$

for the $x$ values $0<x<L . h(x)$ and $M(x)$ are, respectively, the axial displacement and the bending moment of the cantilever at a distance $x$ from the fixed end and $D_{1}$ is the bending modulus per unit width of the cantilever in section. The bending moduli per unit width can be expressed as [52]

$$
D_{1}=\frac{E_{s}^{2} t_{s}^{4}+E_{p}^{2} t_{p}^{4}+2 E_{s} E_{p} t_{s} t_{p}\left(2 t_{s}^{2}+2 t_{p}^{2}+3 t_{s} t_{p}\right)}{12\left(E_{s} t_{s}+E_{p} t_{p}\right)}
$$

where $E_{s}$ and $E_{p}$ are Young's moduli of the nonpiezoelectric and piezoelectric layers, respectively. In order to calculate the tip displacement of the cantilever beam, the following boundary condition has been used: the axial displacement and its first derivative are zero at the fixed end. Mathematically, this can be written as

$$
\begin{gathered}
h_{(x=0)}=0, \\
\left.\frac{d h}{d x}\right|_{x=0}=0 .
\end{gathered}
$$

The axial displacement can be obtained by solving (1) taking into account the boundary conditions given by (3). By integrating (1), one gets

$$
\frac{d h}{d x}=-\int \frac{F}{W D_{1}}[L-x] d x .
$$




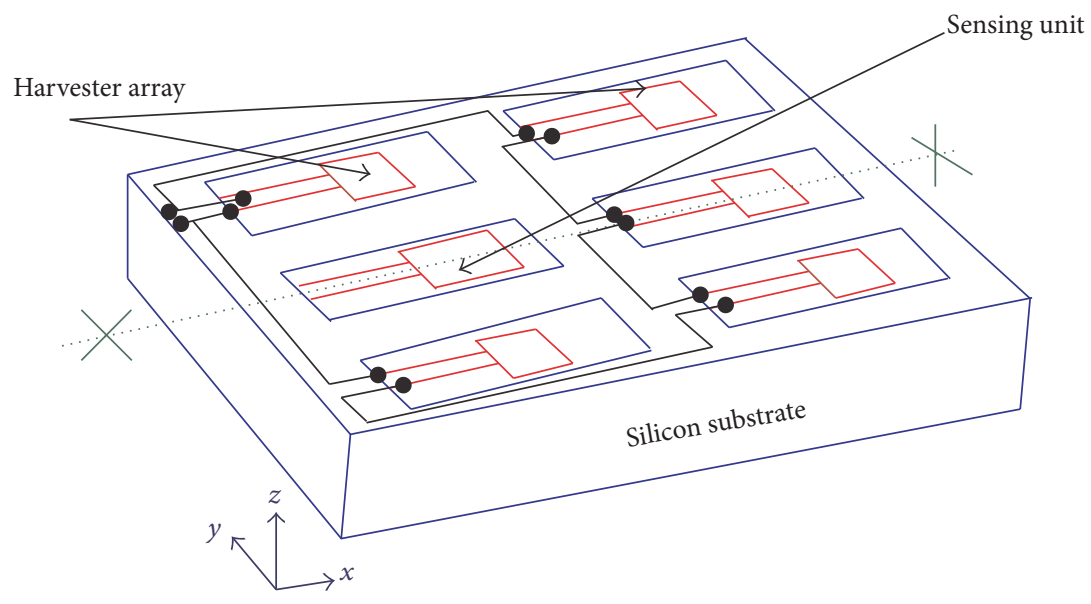

(a)

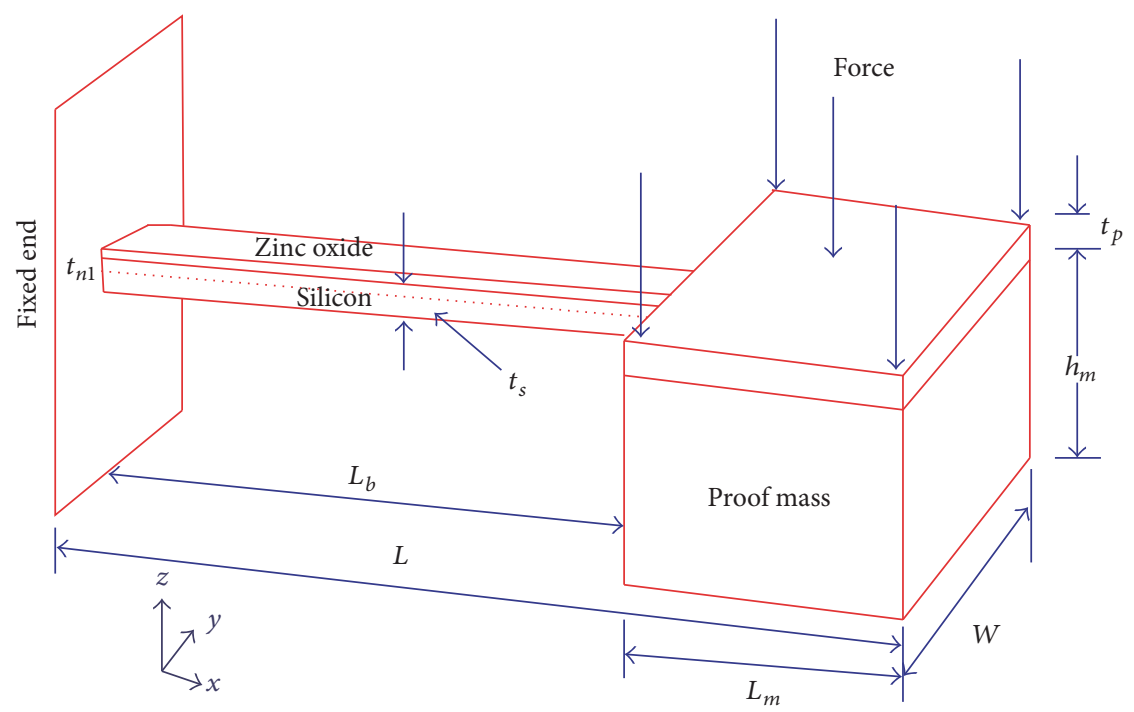

(b)

FIgURE 1: (a) Top view of the accelerometer integrated with array of energy harvesters. (b) Cross-sectional view of an energy harvester/ accelerometer.

This integration gives

$$
\frac{d h}{d x}=-\frac{F}{W D_{1}}\left[L x-\frac{x^{2}}{2}\right]+K_{1} .
$$

Applying the boundary condition, $K_{1}$ is found to be zero. Again integrating (5) and substituting $K_{1}=0$, the displacement $(h)$ is obtained as

$$
h=-\frac{F}{W D_{1}}\left[L \frac{x^{2}}{2}-\frac{x^{3}}{6}\right]+K_{2}
$$

for $0<x<L$. Again it is found that $K_{2}=0$ since $h=0$ at $x=0$. The tip displacement can be obtained by substituting $x=L$ in (6). Thus the tip displacement is obtained as

$$
h_{\text {tip }}=-\frac{F}{W D_{1}}\left[\frac{L^{3}}{3}\right] \text {. }
$$

Here $F$ is the load in $N$. Since the stiffness constant $(K)$ of the beam is defined as the force required for unit tip displacement, it can be obtained from (7) and is given as

$$
K=\frac{F}{h_{\text {tip }}}=\frac{3 W D_{1}}{L^{3}} .
$$

The structure shown in Figure 1(b) has a proof mass that is distributed across an area rather than through a point at the end tip. Therefore, it is treated as a concentrated point load directed through its center of mass which is at distance of $L_{m} / 2$ from the end tip. So, the effective beam length can be written as

$$
L_{\text {eff }}=\left[L-\frac{L_{m}}{2}\right] .
$$

In this condition, the effective spring constant $K^{\prime}$ is given by

$$
K^{\prime}=K\left[\frac{L}{L_{\mathrm{eff}}}\right]^{-3} \text {. }
$$


Using this $K$ equation, the frequencies for the cantilever beams with various lengths have been obtained using the relationship [53]

$$
f_{0}=\frac{v_{n}^{2}}{2 \pi} \sqrt{\frac{0.236 D_{1} W}{\left(L-L_{m} / 2\right)^{3}\left[m_{e}+\Delta m\right]}} .
$$

Here, $D_{1}$ is the bending moduli per unit width, $m_{e}=$ $0.236 \mathrm{~mW}, L$ is the effective mass of the cantilever beam at tip, $v_{n}$ is the $n$th mode eigenvalue $\left(v_{n}^{2}=\sqrt{0.236 / 3}\right), \Delta m$ is the mass of the point proof mass added to the free end tip, $L$ is the total length of the cantilever beam, $W$ is the width of the cantilever beam, and $L_{m}$ is the length of the suspended mass.

3.2. Voltage Analysis. The position of the electrical neutral plane, $t_{n 1}$, can be expressed as [52]

$$
t_{n 1}=\frac{E_{s} t_{s}^{2}-E_{p} t_{p}^{2}}{2\left(E_{s} t_{s}+E_{p} t_{p}\right)}
$$

The lateral strain at any point $(x, z)$ in the beam is

$$
\varepsilon=-\frac{z-t_{n 1}}{r}=\frac{F}{W D_{1}}(L-x)\left(z-t_{n 1}\right)
$$

for $0<x<L$. The lateral stress in the piezoelectric layer $(\mathrm{ZnO})$ can be written as

$$
\sigma=\varepsilon E_{p}=\frac{F E_{p}}{W D_{1}}(L-x)\left(z-t_{n 1}\right)
$$

for $0<x<L$. The induced electric field, $E_{\text {in }}(x, z)$, in the thickness direction at a given $(x, z)$ in the $\mathrm{ZnO}$ piezoelectric layer is therefore

$$
E_{\text {in }}(x, z)=g_{31} \sigma=g_{31} \frac{F E_{p}}{W D_{1}}(L-x)\left(z-t_{n 1}\right)
$$

for $0<x<L$. Here, $g_{31}$ is the piezoelectric coefficient that can be related to the piezoelectric strain coefficient, $d_{31}$, as

$$
g_{31}=\frac{d_{31}}{\varepsilon_{r} \varepsilon_{0}}
$$

where $\varepsilon_{r}$ and $\varepsilon_{0}$ are the dielectric constant of the piezoelectric layer and the permittivity of free space, respectively. By integrating $E_{\text {in }}(x, z)$ with respect to $z$, the induced voltage at any given $x$ is then

$$
V_{\text {in }}(x)=\int_{-t_{p}}^{0} E_{\text {in }}(x, z) d z=g_{31} \frac{F E_{p}(L-x)}{W D_{1}} C_{1}
$$

for $0<x<L$. Here, $C_{1}=\left(t_{n 1} t_{p}+(1 / 2) t_{p}^{2}\right)$ Consider.

$$
V_{\text {in }}(\text { Peak })=\frac{g_{31} F E_{p} L}{W D_{1}} c_{1} \text {. }
$$

The redistribution of induced electric charges on the $\mathrm{ZnO}$ surfaces will now take place so that the top surface has a uniform electrical potential with respect to the bottom surface which also has one single electrical potential. Thus, the measured induced voltage between the two surfaces of the piezoelectric layer should be the average of $V_{\text {in }}(x)$ over the length of the piezoelectric layer, $L$. This can be mathematically written as

$$
V_{\text {in }} \text { avg }=\frac{1}{L} \int_{0}^{L} V_{\text {in }}(x) d x .
$$

Therefore, solving (19), one gets the average induced voltage for cantilever geometries examined in this study. $V_{\text {in }}$ avg is obtained as

$$
V_{\text {in }} \text { avg }=\frac{g_{31} F E_{p}}{2 W D_{1}} L C_{1} .
$$

Here $F$ is the force applied on the surface of the mass. This voltage equation can be used for calculating the voltage induced in piezoelectric energy harvesters as well as accelerometers using a cantilever beam with a suspended mass.

3.3. Charge Sensitivity. Recalling the constitutive equations for a piezoelectric material [54], the charge gathered on the electrode surface can be expressed as the electrical displacement integral on the area of the surface. Then, the charge gathered $(Q)$ can be written as

$$
Q=W_{b} \int_{0}^{L} D_{z} d x=W \int_{0}^{L}\left(e_{31} \varepsilon_{x}+\epsilon_{33} E_{z}\right) d x
$$

where $D_{z}$ is the electrical displacement, $W_{b}$ is the width of the cantilever beam, $e_{31}$ is the piezoelectric coefficient, $\epsilon_{33}$ is the dielectric constant, $E_{z}$ is the electric field applied across the thickness of the layer, and $\varepsilon_{x}$ is the strain experienced by the beam. Assuming that the voltage across the piezoelectric layer is denoted as $V_{\text {avg }}$, the electric field can be approximately expressed assuming uniform electrical field hypotheses. Then,

$$
E_{z}=\frac{-V_{\mathrm{avg}}}{t_{p}}
$$

where $t_{p}$ is the thickness of the piezoelectric layer. Substitution of (22) into (21) and solving it lead to

$$
Q=\frac{W t_{\mathrm{seq}}}{2} e_{31}\left[\left(\varphi(0)-\varphi_{L}\right)\right]-W L \epsilon_{33} \frac{V_{\mathrm{avg}}}{t_{p}},
$$

where $\varphi$ is the slope of deflection of the beam (deformation). Based on (5), it can be written as

$$
\begin{gathered}
\varphi(0)=0, \\
\varphi(L)-\frac{F}{W D_{1}}\left[\frac{L^{2}}{2}\right]
\end{gathered}
$$

and $t_{\text {seq }}$ is the effective thickness of the composite beam. Effective thickness is considered here, since the present cantilever beam is a composite beam of two different materials. The strain must be calculated considering the thickness of 


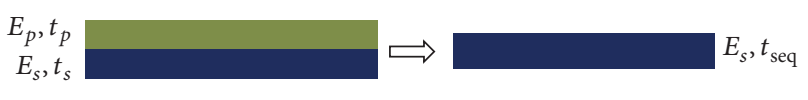

FIGURE 2: Composite beam into a single beam.

both layers. In order to achieve this, the authors convert this composite beam into a simple beam made of nonpiezoelectric material (silicon) as shown in Figure 2.

For the equivalent beam,

$$
E_{s} \times I_{\text {seq }}=W D_{1},
$$

where $E_{s}$ is Young's modulus of the substrate layer $(\mathrm{Si})$ of the beam and $I_{s}$ is the moment of inertia. $W$ is the width of the cantilever beam and $D_{1}$ is the bending modulus per width of the composite beam.

$I_{\text {seq }}$ can be written as

$$
I_{\text {seq }}=\frac{1}{12} W t_{\text {seq }}^{3}
$$

where $t_{\text {seq }}$ is the equivalent thickness of the cantilever beam.

Substituting (2) and (26) into (25), we get

$$
\begin{aligned}
& \frac{1}{12} E_{s} W t_{\mathrm{seq}}^{3} \\
& =W\left[\frac{E_{s}^{2} t_{s}^{2}+E_{p}^{2} t_{p}^{2}+2 E_{s} E_{p} t_{s} t_{p}\left(2 t_{s}^{2}+2 t_{p}^{2}+3 t_{s} t_{p}\right)}{12\left(E_{s} t_{s}+E_{p} t_{p}\right)}\right] .
\end{aligned}
$$

If $\alpha=E_{p} / E_{s}$ (or) $E_{p}=\alpha E_{s}, t_{\text {seq }}$ can be obtained from (26) as

$$
t_{\text {seq }}=\left[\frac{t_{s}^{4}+\alpha^{2} t_{p}^{4}+2 \alpha t_{s} t_{p}\left(2 t_{s}^{2}+2 t_{p}^{2}+3 t_{s} t_{p}\right)}{12\left(t_{s}+\alpha t_{p}\right)}\right]^{1 / 3} .
$$

Substitution of (28) and (24) into (23) gives the charge sensitivity $\left(S_{d}\right)$ as

$$
S_{d}=-\frac{W t_{\mathrm{seq}} e_{31}}{2}\left[\frac{F L^{2}}{2 W D_{1}}\right]+W L \epsilon_{33} \frac{V_{\mathrm{avg}}}{t_{p}},
$$

where $F$ is the applied force in $\mathrm{N} / \mathrm{m}$ at $1 \mathrm{~g}$ and $S_{d}$ is the charge sensitivity in $\mathrm{C} / \mathrm{g}$. Charge sensitivity is an important parameter that decides the performance of piezoelectric accelerometers.

3.4. Background Theory, Simulation Settings, and Material Properties. The simulation studies are carried out using COMSOL Multiphysics 4.1. It is possible to express the relation between the stress, strain, electric field, and electric displacement field in either stress-charge or strain-charge form.

In stress-charge form,

$$
\begin{aligned}
\sigma & =C_{E} \varepsilon-e^{T} E, \\
D & =d \sigma+\varepsilon_{0} \varepsilon_{r s} E .
\end{aligned}
$$

In strain-charge form,

$$
\begin{gathered}
\varepsilon=s_{E} \sigma-d^{T} E \\
D=d \sigma+\varepsilon_{0} \varepsilon_{r} T E .
\end{gathered}
$$

In (30) to (31) $\sigma$ is the mechanical stress vector, $s_{E}$ the elastic compliance tensor $\left(\mathrm{Pa}^{-1}\right), T$ is the mechanical stress vector $\left(\mathrm{Nm}^{-2}\right), C_{E}$ is the elasticity matrix, $e^{T}$ is the stress coupling matrix, $\varepsilon$ is the mechanical strain vector, $D$ is the electric displacement vector $\left(\mathrm{Cm}^{-2}\right), \varepsilon^{T}$ is the dielectric permittivity tensor $\left(\mathrm{Fm}^{-1}\right), E$ is the electric field vector $\left(\mathrm{Vm}^{-1}\right)$, and $d$ is the transverse piezoelectric coefficient tensor $\left(\mathrm{CN}^{-1}\right)$. For most materials, data appears in the strain-charge form, and one can easily transform it into the stress-charge form. COMSOL Multiphysics can use both constitutive forms; simply select one, and software makes any necessary transformation. The following equations transform strain-charge material data to stress-charge data:

$$
\begin{aligned}
C_{E} & =s_{E}^{-1}, \\
e & =d s_{E}^{-1} d^{T}
\end{aligned}
$$

and by substitution

$$
\begin{aligned}
\varepsilon_{s} & =\varepsilon_{T}-d s_{E}^{-1} d^{T}, \\
\varepsilon_{T} & =\varepsilon_{0} \varepsilon_{r} T
\end{aligned}
$$

The cantilever beam is fixed at the $y z$ plane at the fixed end as shown in Figure 1(b) and all other planes are free. The system applies a floating potential difference between the top and bottom surfaces of the cantilever beam. This gives rise to an electric field perpendicular to the poling direction $(z$ direction) and thus induces a transverse shear strain. Zero charges are assumed at the $y z$ plane at the fixed end.

The piezoelectric material chosen for this study is $\mathrm{ZnO}$. Elasticity matrix $\left(C_{E}\right)$ and relative permittivity matrix $\left(\varepsilon_{r s}\right)$ used in the computation are as follows:

Elasticity matrix (ordering: $x x, y y, z z, y z, x z$, and $x y)$ is

$$
C_{E}=\left[\begin{array}{cccccc}
209 & 121.1 & 105 & 0 & 0 & 0 \\
0 & 209 & 105 & 0 & 0 & 0 \\
0 & 0 & 211 & 0 & 0 & 0 \\
0 & 0 & 0 & 42.3 & 0 & 0 \\
0 & 0 & 0 & 0 & 42.3 & 0 \\
0 & 0 & 0 & 0 & 0 & 44.2
\end{array}\right] \text { [GPa]. }
$$

Coupling matrix is

$$
e_{E s}=\left[\begin{array}{ccc}
0 & 0 & -0.567 \\
0 & 0 & -0.567 \\
0 & 0 & 1.032 \\
0 & 0 & 0 \\
0 & -0.480 & 0 \\
-0.480 & 0 & 0
\end{array}\right]\left[\mathrm{C} / \mathrm{m}^{2}\right] \text {. }
$$


TABLE 1: Harvester fundamental frequencies.

\begin{tabular}{lc}
\hline Harvester & Frequency in $\mathrm{Hz}$ \\
\hline PEH-A & 10 \\
PEH-B & 15 \\
PEH-C & 20 \\
PEH-D & 25 \\
PEH-E & 30 \\
\hline
\end{tabular}

Relative permittivity is

$$
\varepsilon_{r s}=\left[\begin{array}{ccc}
8.546 & 0 & 0 \\
0 & 8.546 & 0 \\
0 & 0 & 10.204
\end{array}\right][\mathrm{F} / \mathrm{m}] \text {. }
$$

The deformation of the cantilever beam is based on the corresponding applied force $(\mathrm{N})$ and the beam induced bending action.

\section{Design Approach for Energy Harvesters for Wireless SHM of Bridges}

The main aim of this study is to design energy harvesters that gather energy from vibrations induced in the bridges by the passing vehicles and use the same energy for transmitting the vibration signal picked up by the micro accelerometers to the remote receiver by wireless sensor node. This would improve the battery life time. It is already known that the natural frequencies of the bridges are low in general and would vary as the structures undergo damage due to aging or other natural phenomena. Further, it is true that the energies generated by low frequency harvesters can be high. Hence, this research work focuses on an array of energy harvesters that have closely separated resonant frequencies that match the resonant frequencies of the structure under monitor. These harvesters are then connected in parallel to produce the maximum power and harvest the required power for transmission activities during the service period of the structure under the monitor. With this agenda, the authors have designed five piezoelectric energy harvesters, namely, $\mathrm{PEH}-\mathrm{A}$ to $\mathrm{PEH}-\mathrm{E}$, with their frequency specifications listed in Table 1.

In this work, the authors assume a bridge that has a natural frequency of $30 \mathrm{~Hz}$ at virgin condition and expected to fall up to $10 \mathrm{~Hz}$ as damage is introduced in the course of its service period.

4.1. Design of the Piezoelectric Energy Harvesters. This section presents the design of the devices PEH-A to PEH-E listed in Table 1. It is true that the energy harvesters do not fall into the category of devices that show improvement in performance or efficiency when down scaled or miniaturized. Therefore upscaling is the only option. However, to match the current trend for making small devices, the energy harvesters must be made as small as possible. At the same time, wireless SHM needs power in the order of at least $25 \mathrm{~mW}$ [55] for transmission from sensor node in a wireless sensor network and it is also true that generated power from bridges can range from $10 \mu \mathrm{W}$ to $500 \mu \mathrm{W}$ [56] depending on the bridge length, the vehicle velocity, and the location of installation of the energy harvesters in the bridges. Taking these factors into account, devices with different beam length $\left(L_{b}\right)$, beam width $\left(W_{b}\right)$, and mass size $\left(L_{m}\right.$ or $\left.W_{m}\right)$ have been simulated using COMSOL Multiphysics. The results on the dependency of the fundamental frequency on these parameters thus obtained by simulation for various devices are plotted as shown in Figures 3(a)-3(c) along with the analytical frequency values obtained using the following equation for mass and the equation for frequency $\left(f_{0}\right)$ given in Section 3.1:

$$
\begin{aligned}
m= & 0.236\left[\left(\rho_{P} L_{\mathrm{eff}} W t_{p}\right)+\left(\rho_{s} L_{\mathrm{eff}} W t_{s}\right)\right] \\
& +\left(\rho_{s} L_{m} W_{m} H_{m}\right) .
\end{aligned}
$$

A closer look at the results shows that the frequency can be varied from $10 \mathrm{~Hz}$ to $30 \mathrm{~Hz}$ by just varying width $\left(W_{b}\right)$ from $1000 \mu \mathrm{m}$ to $7000 \mu \mathrm{m}$ for the length $L_{b}=20 \mathrm{~mm}$ and $L_{m}=$ $W_{m}=15 \mathrm{~mm}$. This is preferred because the harvesters of the array will be of the same length and therefore die size can be minimized. The thickness of the piezoelectric layer $\left(t_{p}\right)$ and a substrate layer $\left(t_{s}\right)$ is designed to achieve maximum voltage induction as discussed in Section 3.2. The various dimensions of the devices thus designed are given in Table 2.

4.2. Deflection and Voltage Analysis. This section discusses the results of the deflection and voltage analyses conducted on the five energy harvesters designed and described in the previous section. Figure 4(a) shows the device PEH-A cantilever type energy harvester created for simulation in the COMSOL Multiphysics environment. The figure also shows the displacement and voltage induced at a force of $F=$ $2.1 \mathrm{mN}$. This corresponds to the force acting on the surface of the cantilever beam for a vibration of $1 \mathrm{~g}$. The device "A" generates a peak voltage of $77.35 \mathrm{~V}$ at this force developed at a vibration of $1 \mathrm{~g}$. The tip displacement is obtained as $2.06 \mathrm{~mm}$ for the same case. The displacement at various points over the length of the beam is also shown in Figure 4(b). The voltage profile along the length of the beam at $\mathrm{W}_{b} / 2$ is shown in Figure $4(\mathrm{c})$. Figure 5 gives the displacement obtained for these devices PEH-A to PEH-E at force $(F)=2.1 \mathrm{mN}$ or $g=1$. The displacements and induced peak voltages thus obtained for other devices are summarized in Table 3.

Figure 5 gives deflection profile of the beam for the acceleration of $g=1$ in the devices PEH-A to PEH-E.

4.3. Equivalent Circuit Modeling with OrCAD and Deflection Analysis. In order to further validate the simulation results, the inertial based energy harvester devices PEH-A to PEH-E are modeled as second-order spring-mass-damper mechanical systems. The model equation of such a mechanical system resembles the $I-V$ relationship in $R-L-C$ series circuit. Therefore, electrical equivalent circuits of the mechanical spring-mass-damper systems are derived and analysed to find the voltages and currents in the equivalent circuits. These current and voltage values are then used to compute the deflection and other mechanical parameters in the original energy harvesters. 


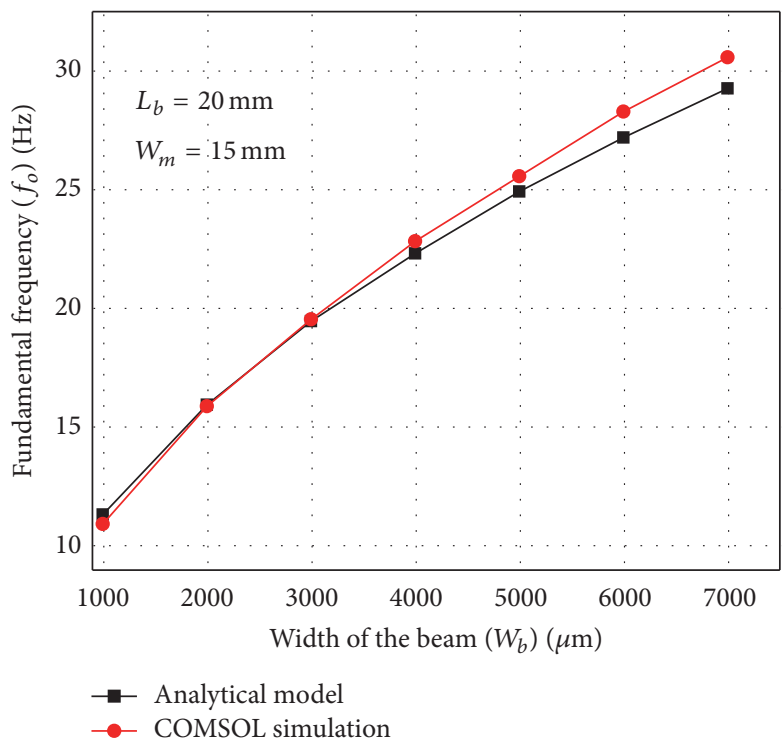

(a)

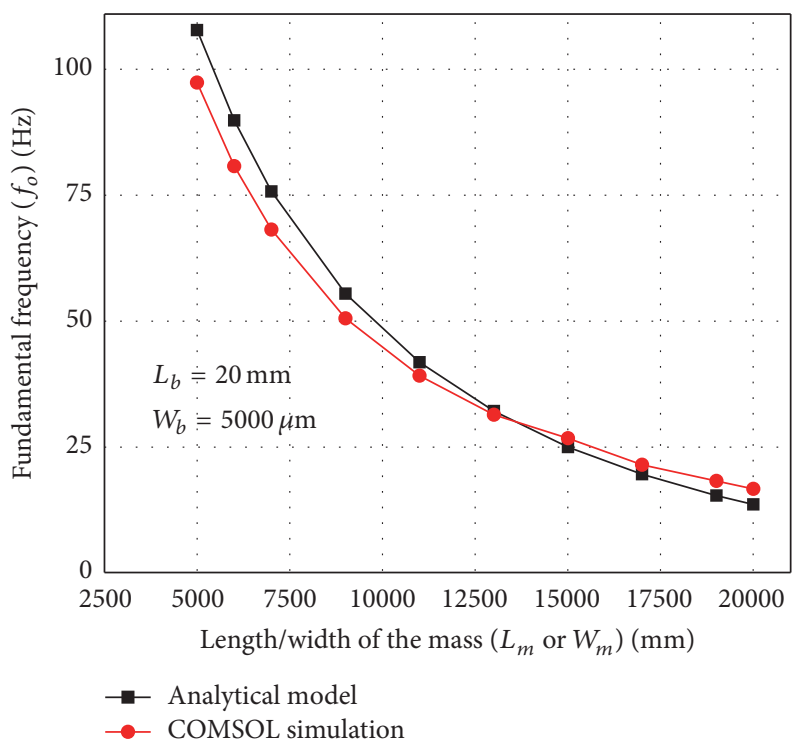

(b)

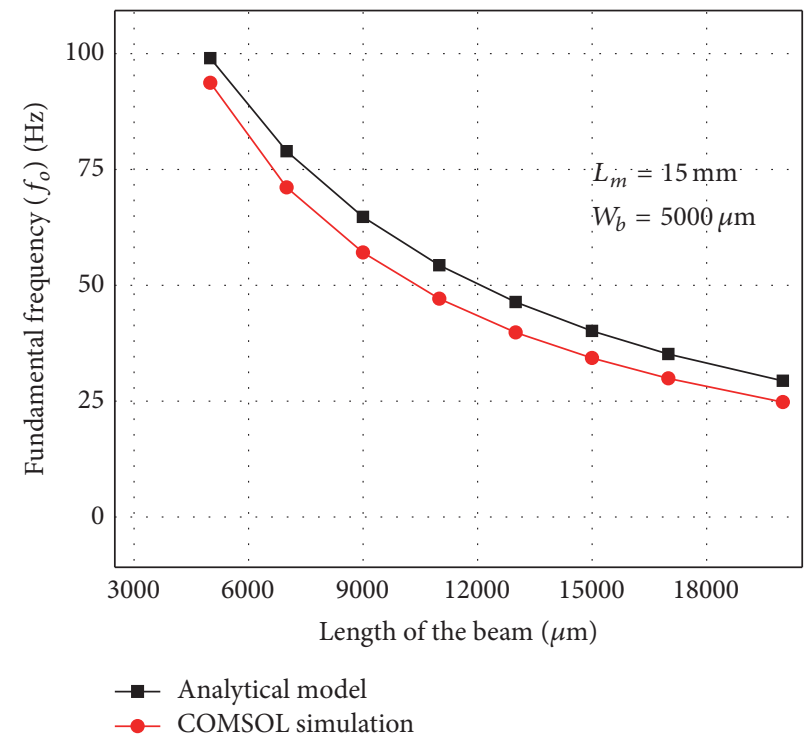

(c)

FIGURE 3: (a) Fundamental frequency of the cantilever beam harvesters with beam width $\left(W_{b}\right)$. (b) Fundamental frequency of the harvesters with mass size $\left(L_{m}\right.$ or $\left.W_{m}\right)$. (c) Fundamental frequency of the harvesters with beam length $\left(L_{b}\right)$.

TABLE 2: Geometrics of the energy harvesters.

\begin{tabular}{|c|c|c|c|c|c|c|}
\hline $\begin{array}{l}\text { Beam } \\
\text { model }\end{array}$ & $\begin{array}{l}\text { Length } \\
\left(L_{b}\right) \text { in } \mathrm{mm}\end{array}$ & $\begin{array}{l}\text { Length of the mass } \\
\left(L_{m}\right) \text { in } \mathrm{mm}\end{array}$ & $\begin{array}{l}\text { Beam width }\left(W_{b}\right) \\
\text { in } \mu \mathrm{m}\end{array}$ & $\begin{array}{c}\text { Thickness of the } \\
\text { piezoelectric layer }\left(t_{p}\right) \text { in } \\
\mu \mathrm{m}\end{array}$ & $\begin{array}{l}\text { Thickness of the silicon } \\
\text { layer }\left(t_{s}\right) \text { in } \mu \mathrm{m}\end{array}$ & $\begin{array}{c}\text { Natural } \\
\text { frequency in } \mathrm{Hz}\end{array}$ \\
\hline PEH-A & 20 & 15 & 1000 & 45 & 50 & 10.94 \\
\hline PEH-B & 20 & 15 & 2000 & 45 & 50 & 15.89 \\
\hline PEH-C & 20 & 15 & 3000 & 45 & 50 & 19.55 \\
\hline PEH-D & 20 & 15 & 5000 & 45 & 50 & 25.57 \\
\hline PEH-E & 20 & 15 & 7000 & 45 & 50 & 30.57 \\
\hline
\end{tabular}




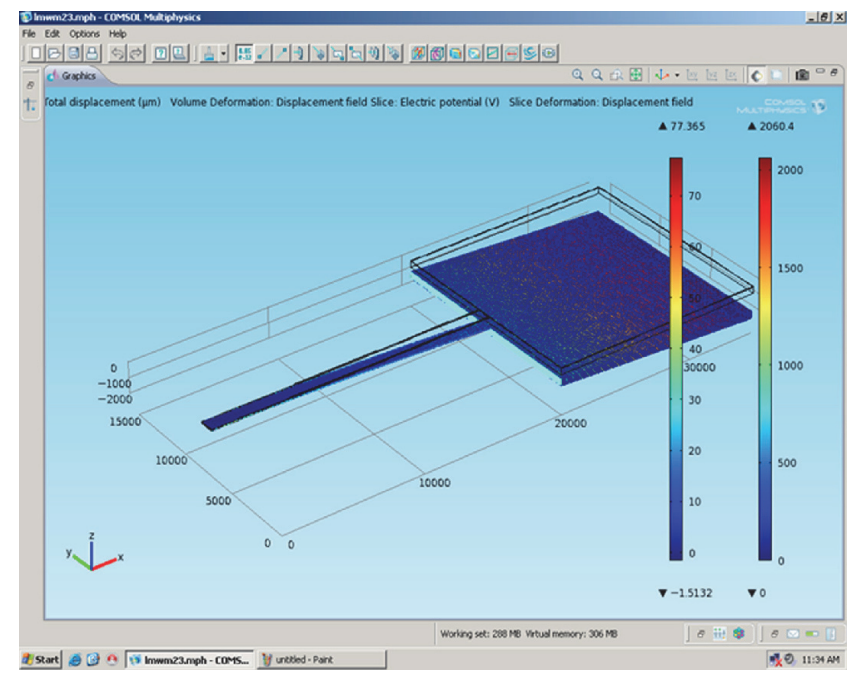

(a)

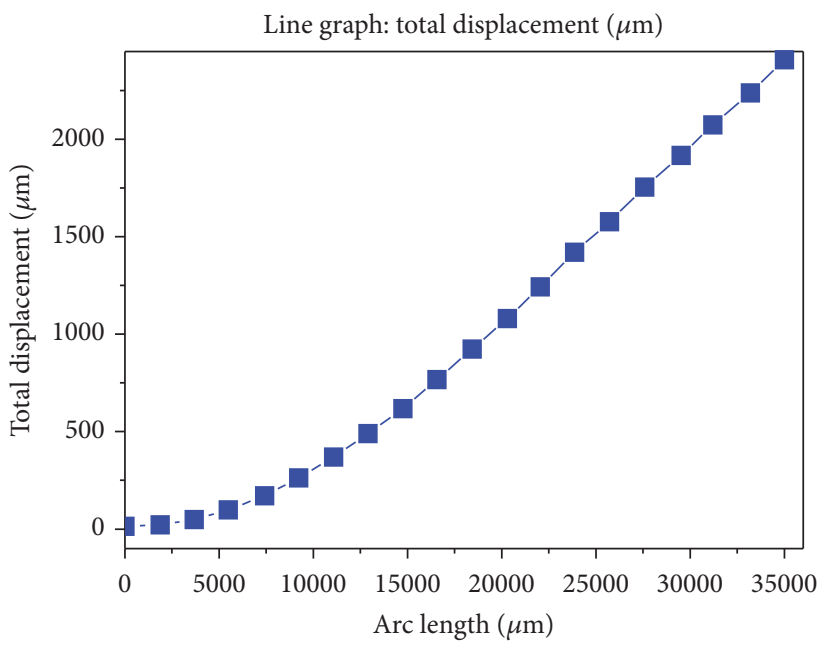

(b)

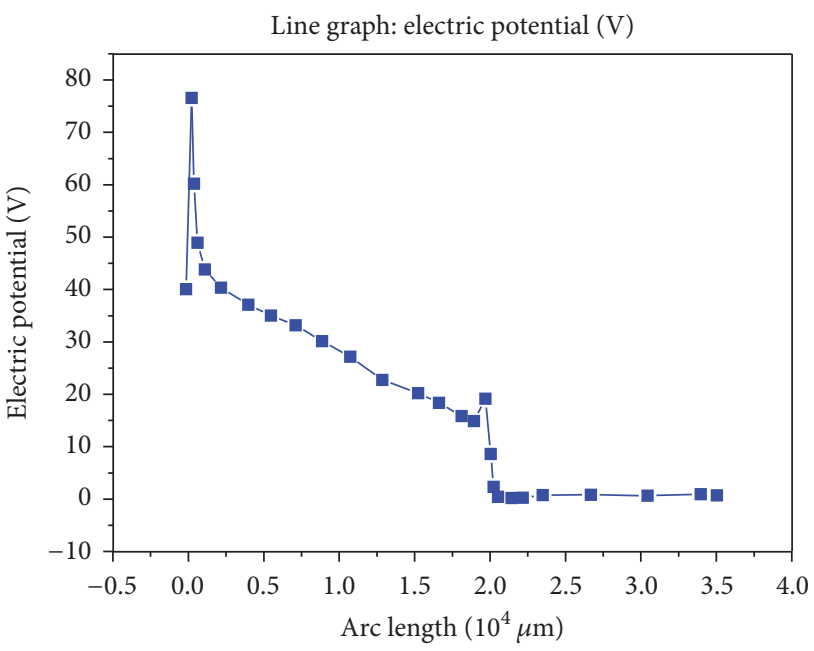

(c)

FIgure 4: (a) Piezoelectric energy harvester (device PEH-A) created for simulation in COMSOL Multiphysics environment. (b) Deflection of the piezoelectric cantilever (device PEH-A). (c) Induced peak voltage of the piezoelectric cantilever beam in device $\mathrm{PEH}-\mathrm{A}$ at $F=2.1 \mathrm{mN}$ $(g=1)$.

TABLE 3: Displacement and induced voltages at $F=2.1 \mathrm{mN}(g=1)$.

\begin{tabular}{lcc}
\hline Device model & Displacement $(\mu \mathrm{m})$ & Induced peak voltage (volts) \\
\hline PEH-A & 2060.0 & 77.35 \\
PEH-B & 1010.0 & 38.09 \\
PEH-C & 668.4 & 26.71 \\
PEH-D & 393.7 & 16.38 \\
PEH-E & 287.6 & 12.62 \\
\hline
\end{tabular}

In the spring-mass-damper systems, the mass of the excitation source is much larger than mass of the harvester. So, the excitation source is not damped by the energy harvester and thus it is assumed to provide infinite power. The force balance under this condition is given as

$$
m a=m \ddot{z}+d \dot{z}+k_{s} z+F_{e},
$$

where " $a$ " indicates the acceleration acting on the harvester frame. So, " $m a$ " represents the external force which is being exerted on the harvester frame. " $d$ " is the damping constant which represents the mechanical damping due to friction and air resistance. Due to electromechanical feedback, the transducer exerts a restoring force $F_{e}$ on the seismic mass if an interface circuit is connected, causing additional electrical damping $d_{e} . k_{s}$ represents the stiffness constant of the cantilever beam and $m$ is the mass suspended on the spring. The deflection is given by $z$ in this equation. If the restoring force is considered as a damping force $F_{e}=d_{e} \dot{z}$, (38) can be rewritten as

$$
m a=m \ddot{z}+\left(d+d_{e}\right) \dot{z}+k_{s} z
$$

A closer look at this equation indicates that it resembles the mesh equation of an $R-L-C$ series circuit energized with a 


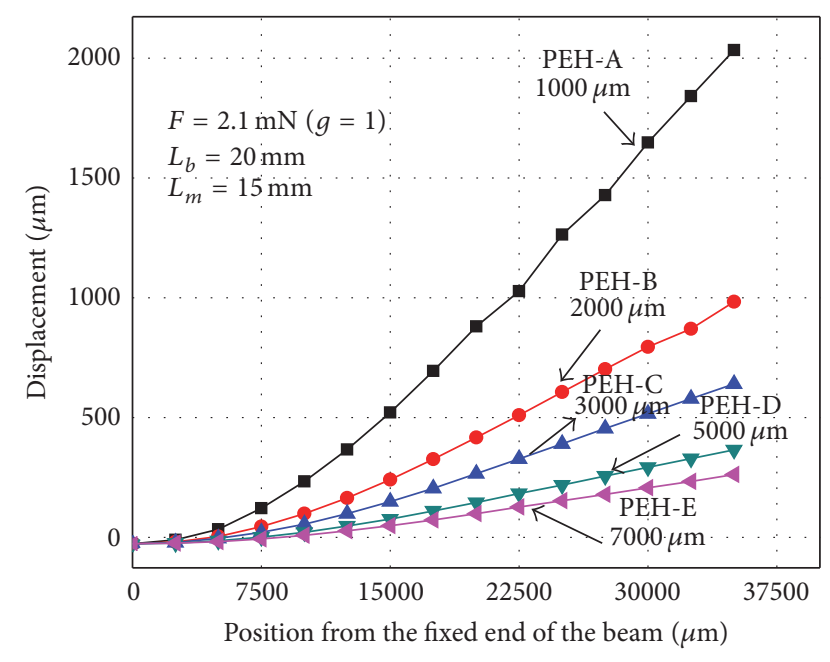

Figure 5: Displacement at various points of the beams in devices PEH-A to PEH-E obtained using COMSOL Multiphysics.

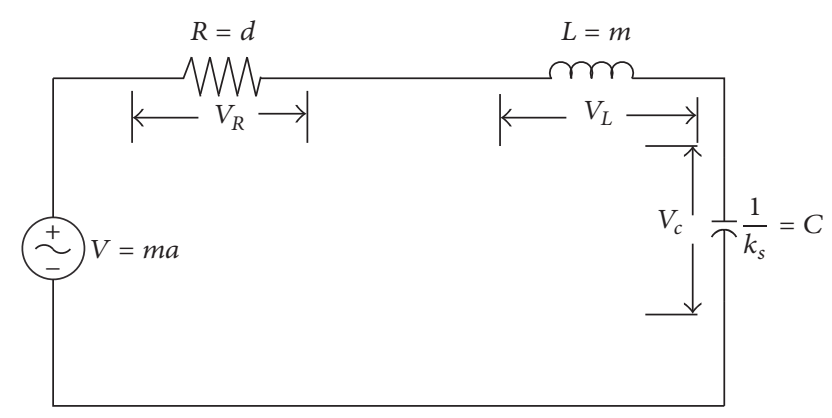

FIGURE 6: Equivalent circuit of the piezoelectric cantilever beam.

voltage " $V$ " equivalent to the force $F=m a$ here. In an $R-L$ $C$ circuit the current and voltage are related by the equation

$$
V=L \frac{d i}{d t}+\frac{1}{c} \int i d t+i R
$$

If $i=d z / d t$, (40) can be rewritten as

$$
m a=m \frac{d i}{d t}+K_{s} \int i d t+\left(d+d_{e}\right) i
$$

From comparison of (40) and (41), it is true that

$$
\begin{aligned}
V & =m a, \\
L & =m, \\
k_{s} & =\frac{1}{c}, \\
\text { or } c & =\frac{1}{k_{s}}, \\
R & =d+d_{e} .
\end{aligned}
$$

Hence, the equivalent circuit will be given as shown in Figure 6.
The equivalent resistances $R, L$, and $C$ for all the piezoelectric energy harvesters are calculated to obtain the equivalent electrical circuits for all the harvesters PEH-A to PEH-E considered in this study. These parameters are summarized in Table 4 . The damping constant " $d$ " is calculated using the relationship

$$
d=2 m \omega_{n} \zeta
$$

by substituting, $\omega_{n}=2 \pi f_{0}$ and " $\zeta$ " is the damping ratio.

In order to get the displacement at various frequencies of vibration for different energy harvesters, the following technique is adopted. The current flowing through this circuit will be equal to $d z / d t$. Therefore, measurement of current will only give the velocity $d z / d t$. But the required quantity is the displacement $(z)$. The capacitor voltage $\left(V_{c}\right)$ is equal to $z / t$ since $i=d z / d t$. Hence, the capacitor voltage $\left(V_{c}\right)$ is measured through OrCAD simulation. This voltage $\left(V_{c}\right)$ is then multiplied by value of " $C$ " to directly get the displacement.

The OrCAD circuit simulator is used to simulate the five equivalent electrical circuits of the energy harvesters $\mathrm{PEH}-$ A to PEH-E. The voltage $V$ is set at $2.1 \mathrm{~V}$ in the place of $2.1 \mathrm{mV}$. The $R$ and $L$ values are set at $10^{3}$ times of the $R$ and $L$ values given in Table 4 . The capacitor value is chosen to be $10^{-3}$ times of the value obtained and given in Table 4 . Now, the capacitor voltage $\left(V_{c}\right)$ for all the five generators is obtained at various frequencies in the frequency range of $1 \mathrm{~Hz}$ to $1 \mathrm{kHz}$. The capacitor voltage thus obtained is plotted against frequency as shown in Figure 7(a) and thus indirectly gives the displacement obtained for these energy harvesters at $1 \mathrm{~g}$ vibration at different frequencies. Here, the design used the damping coefficient $(\xi)$ to be 0.5 . This voltage is multiplied by the value of " $C$ " to get the displacement as shown in Figure 7(b).

These displacement results closely match the displacements obtained using COMSOL and presented in Section 4.2.

\subsection{Equivalent Circuit of Energy Harvesters and Power Analy-} sis. It can be seen from various literatures $[57,58]$ that the piezoelectric energy harvester can be modeled ideally as a voltage source with a voltage $(V)$ in series with the static capacitance $\left(C_{p}\right)$ of the cantilever beam. This overall static capacitance $\left(C_{p}\right)$ can be obtained simply from parallel plate capacitance equation

$$
C_{p}=\frac{\varepsilon_{o} \varepsilon_{r} A}{t_{p}}
$$

where $\varepsilon_{r}$ is relative permittivity of the piezoelectric material, $\varepsilon_{o}$ is relative permittivity of free space, $A$ is area, and $t_{p}$ is the thickness of the piezoelectric material layer.

When dielectric losses are considered, then a resistor $\left(R_{p}\right)$ is connected parallel. This resistance $\left(R_{p}\right)$ is calculated from the formula

$$
R_{p}=\frac{\rho l}{A}
$$

Here, $\rho$ is considered as $750 \mathrm{k} \Omega-\mathrm{m}$ for $\mathrm{ZnO}$. The electrical equivalent circuit of a piezoelectric energy harvester is shown 


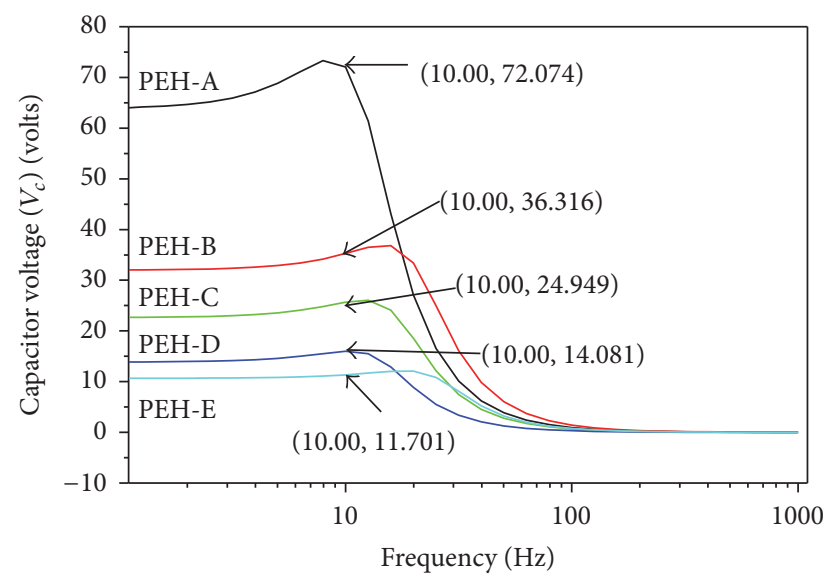

(a)

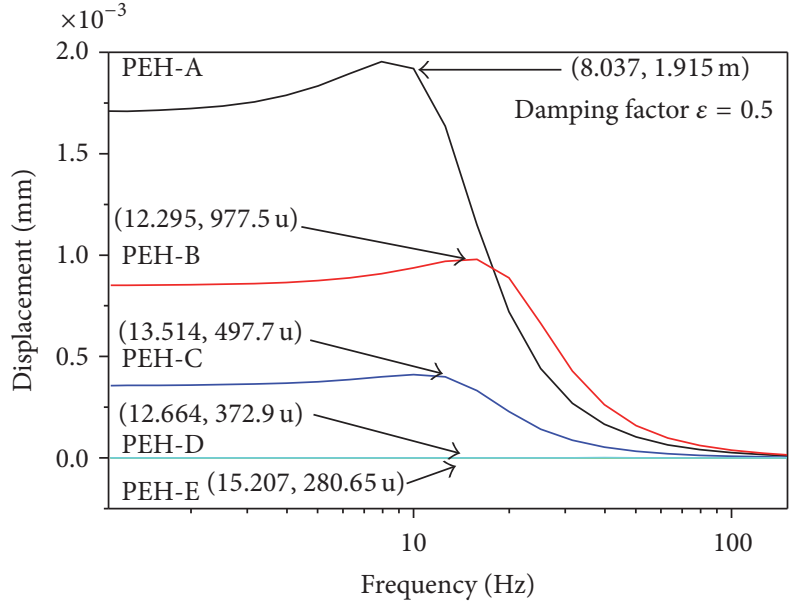

(b)

FIGURE 7: (a) Capacitor voltage $\left(V_{c}\right)$ obtained for the harvesters PEH-A to PEH-E at various frequencies of vibrations. (b) Displacement response of piezoelectric cantilever beam with proof mass for devices $\mathrm{PEH}-\mathrm{A}$ to $\mathrm{PEH}-\mathrm{E}$ at various frequencies of vibrations.

TABLE 4: Parameters of the energy harvester's equivalent electrical circuit.

\begin{tabular}{lcccc}
\hline Device code & Source voltage $(\mathrm{mV})$ & Resistance $(R)$ in $\mathrm{m} \Omega$ & Inductor $(L)$ in $\mathrm{mH}$ & Capacitance $(C)$ in $\mathrm{F}$ \\
\hline PEH-A & 2.1 & 16.2 & 0.2114 & 0.8095 \\
PEH-B & 2.1 & 23.0 & 0.2132 & 0.4048 \\
PEH-C & 2.1 & 28.2 & 0.2149 & 0.2698 \\
PEH-D & 2.1 & 36.2 & 0.2184 & 0.1691 \\
PEH-E & 2.1 & 43.8 & 0.2210 & 0.1156 \\
\hline
\end{tabular}

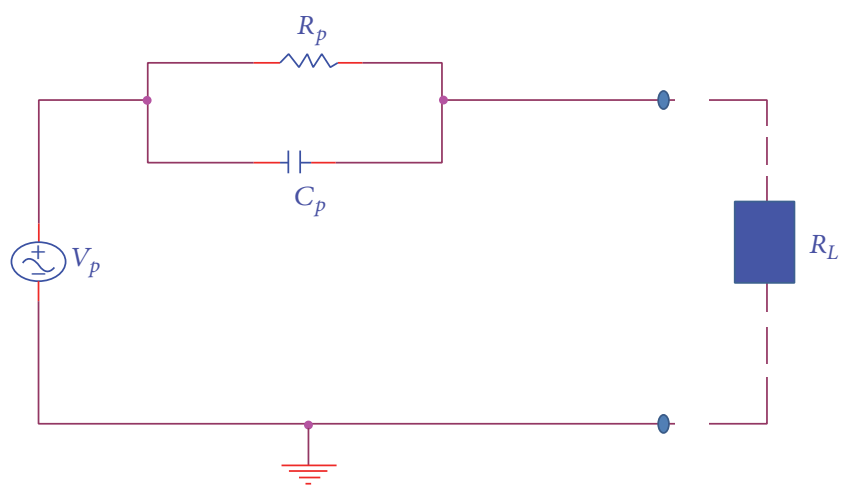

FIGURE 8: Equivalent circuit of the piezoelectric beam energy harvester.

in Figure 8. The voltage $(V)$ is the induced voltage for a given vibration or acceleration. This voltage can be obtained by analytical modeling or by simulation.

Here, the induced voltages were obtained using the following approach.

The deflections in the range of $0-2 \mathrm{~g}$ have been calculated by different approaches as explained in the previous sections. The induced voltages at various " $g$ " also have been obtained using COMSOL Multiphysics simulation. The induced voltage obtained for various deflections has been plotted for all the five piezoelectric harvesters from the $\delta-\mathrm{g}$ and $V_{p}-\mathrm{g}$ observations plotted as shown in Figures 9(a) and 9(b).
TABLE 5: Estimation of induced voltages from OrCAD and COMSOL simulation for various energy harvesters.

\begin{tabular}{lccc}
\hline Device & $\alpha=\Delta V / \Delta \delta(\mathrm{V} / \mu \mathrm{m})$ & $\beta=\Delta \delta / \Delta g(\mu \mathrm{m} / \mathrm{g})$ & $\mathrm{V}_{\text {ind }}=\alpha \beta$ \\
\hline PEH-A & 0.03754 & 2009.4 & 71.13 \\
PEH-B & 0.03764 & 1012.2 & 38.09 \\
PEH-C & 0.03995 & 668.1 & 26.69 \\
PEH-D & 0.03886 & 420.6 & 16.34 \\
PEH-E & 0.04388 & 288.0 & 12.63 \\
\hline
\end{tabular}

TABLE 6: Equivalent circuit parameters of the energy harvester.

\begin{tabular}{lccc}
\hline Model & $\begin{array}{c}\text { Resistance } \\
\left(R_{p}\right) \text { in } \mathrm{M} \Omega\end{array}$ & $\begin{array}{c}\text { Capacitance } \\
\left(C_{p}\right) \text { in } \mathrm{pF}\end{array}$ & $\begin{array}{c}\text { Voltage } \\
\text { at } 10 \mathrm{~Hz} \text { in volts }\end{array}$ \\
\hline PEH-A & 1.685 & 40.15 & 72.07 \\
PEH-B & 0.843 & 80.30 & 36.31 \\
PEH-C & 0.562 & 120.40 & 24.94 \\
PEH-D & 0.337 & 200.70 & 14.08 \\
PEH-E & 0.241 & 281.00 & 11.70 \\
\hline
\end{tabular}

From Figures 9(a) and 9(b), the displacement versus induced voltage relationship is obtained and plotted as shown in Figure 9(c). Therefore, the displacement per unit " $g$ " acceleration $(\beta)$ and the voltage induced per unit displacement $(\alpha)$ obtained experimentally can be used to calculate the induced voltage $\left(V_{\text {ind }}\right)$ as summarized in Table 5 . Thus the equivalent circuits of energy harvesters PEH-A to PEH-E are calculated and listed in Table 6. However, the deflection of 


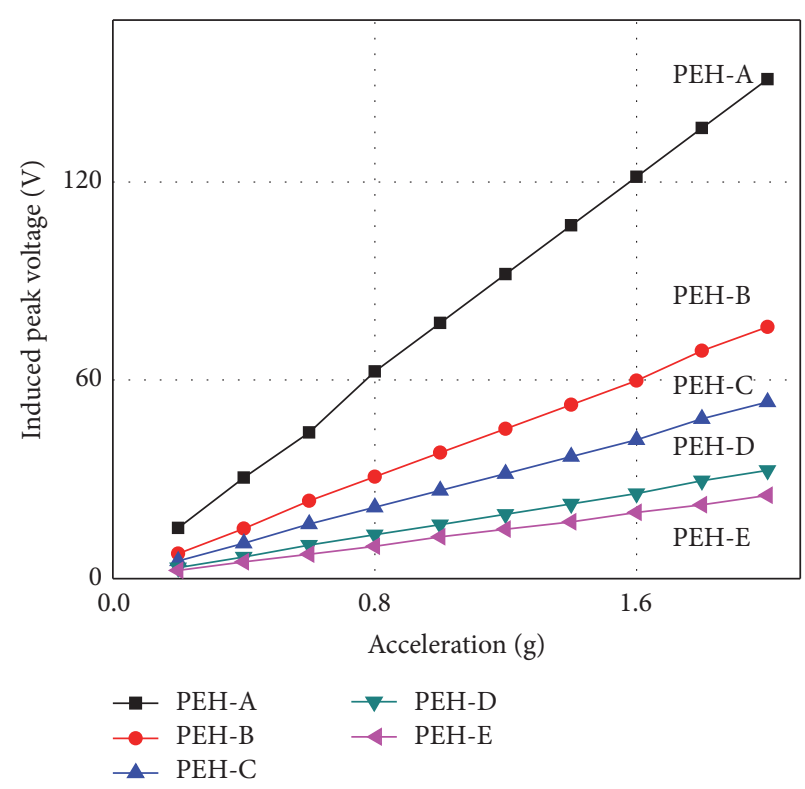

(a)

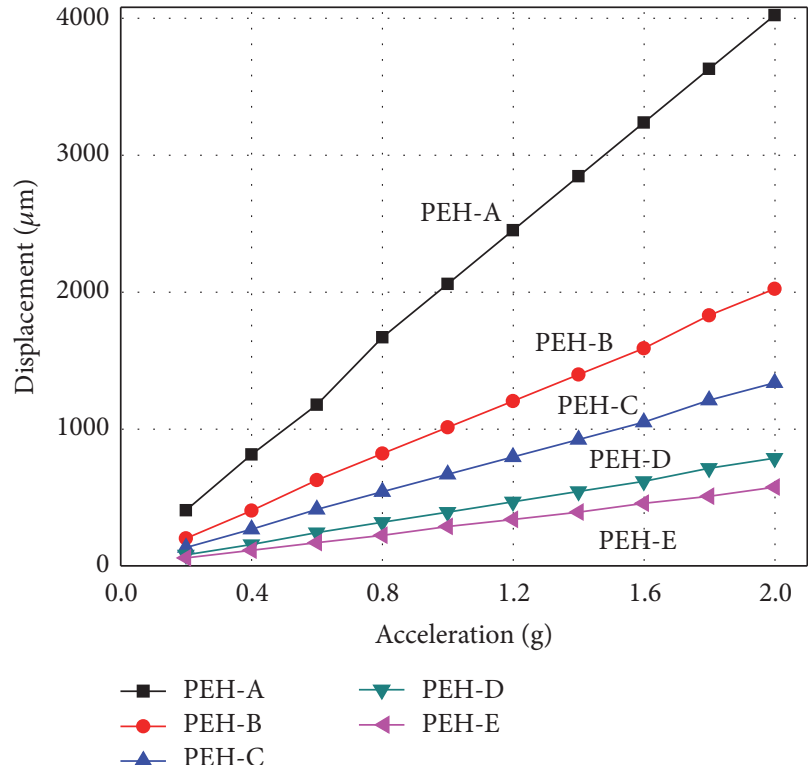

(b)

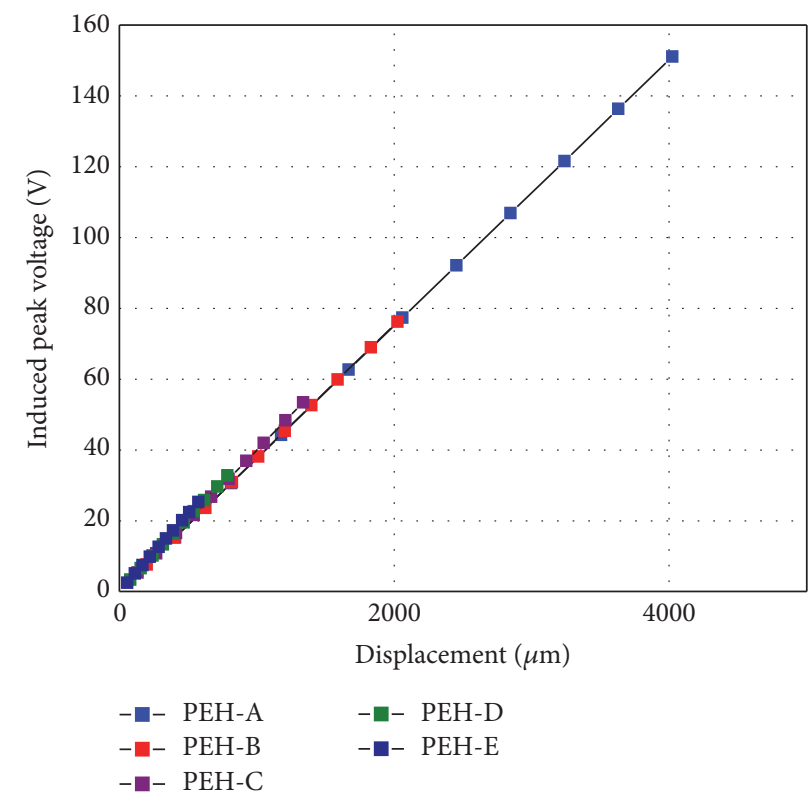

(c)

Figure 9: (a) Induced peak voltage versus gravity obtained from COMSOL Multiphysics. (b) Displacement versus gravity obtained from COMSOL Multiphysics. (c) Displacement versus induced peak voltage obtained from COMSOL Multiphysics.

the cantilever beam can vary depending on the frequency of the vibration source and therefore induced voltage would vary with frequency. Table 6 gives the induced voltage at $f=10 \mathrm{~Hz}$.

From the above-mentioned parameters, the equivalent circuit parameters of the five different harvesters have been obtained and summarized in Table 6.

4.4.1. Power Analysis at Various Loads. This section analyses the power harvested from the five different energy harvesters independently at various loads. The equivalent circuit of each harvester is used to estimate the power harvested at various load conditions. OrCAD circuit simulator has been used for this purpose. Table 7 summarizes the peak power harvested by various harvesters at $1 \mathrm{~g}$ and the load at which maximum power is transferred.

Subsequently, the harvested power at various loads $\left(R_{L}\right)$ for all the five devices is estimated at three vibration frequencies, namely, $10 \mathrm{~Hz}, 20 \mathrm{~Hz}$, and $30 \mathrm{~Hz}$. These results are plotted in Figures 10(a), 10(b), and 10(c), respectively.

These results show that the energy harvester designed for the lowest frequency gives the maximum power output when 


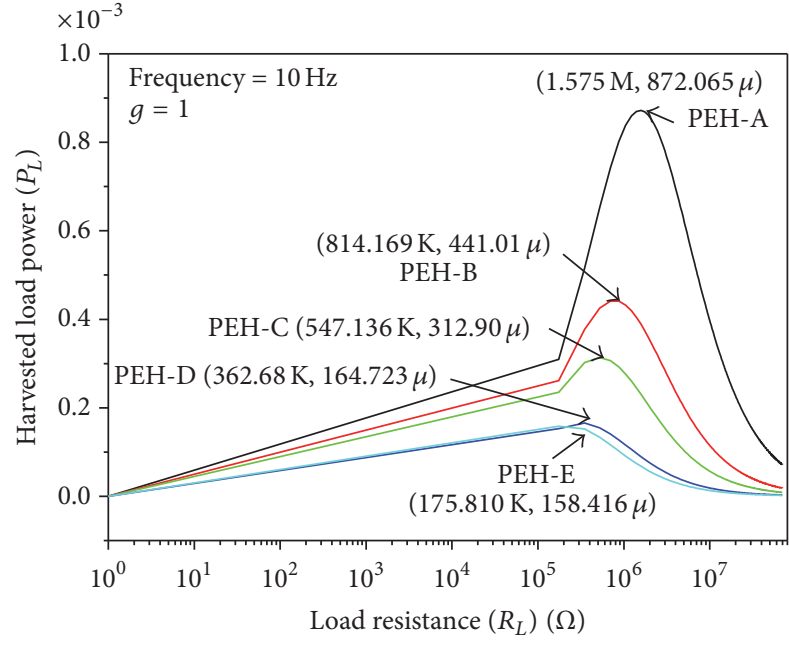

(a)

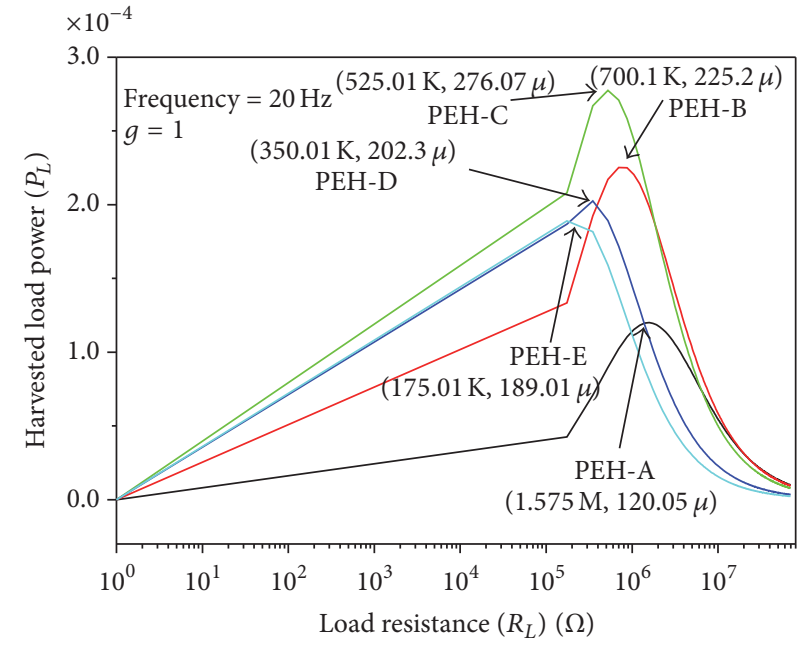

(b)

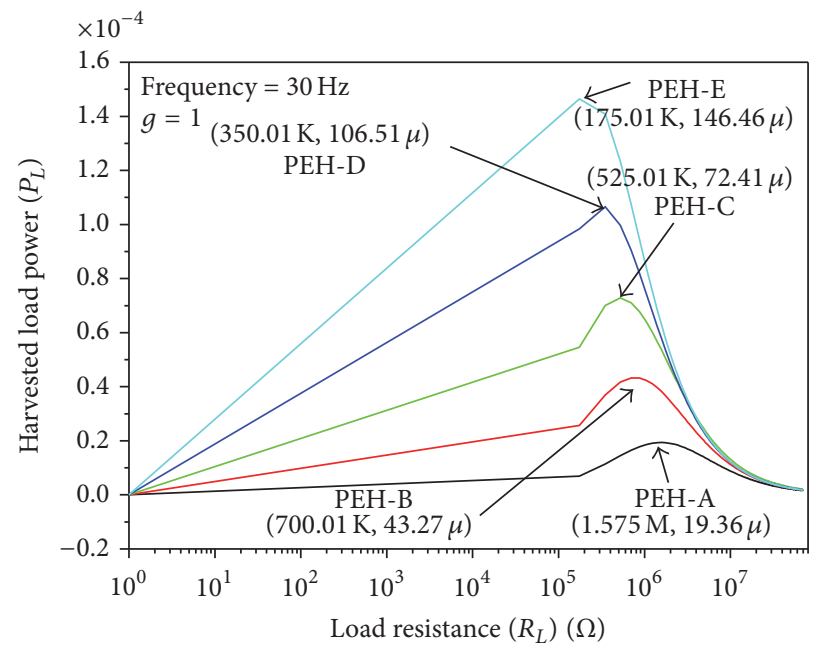

(c)

FIgURE 10: (a) Output power of the energy harvester PEH-A to PEH-E at various loads at frequency $10 \mathrm{~Hz}$. (b) Output power of the energy harvester PEH-A to PEH-E at various loads at frequency $20 \mathrm{~Hz}$. (c) Output power of the energy harvester PEH-A to PEH-E at various loads at frequency $30 \mathrm{~Hz}$.

TABLE 7: Geometrics of the energy harvester at $F=2.1 \mathrm{mN}$ or $g=1$.

\begin{tabular}{lcccc}
\hline Harvester & $\begin{array}{c}R_{L} \text { at peak } \\
\text { power } \\
\text { in } \mathrm{K} \Omega\end{array}$ & $\begin{array}{c}\text { Maximum } \\
\text { power } \\
\text { in } \mu \mathrm{W} \\
\text { at } 10 \mathrm{~Hz}\end{array}$ & $\begin{array}{c}\text { Maximum } \\
\text { power } \\
\text { in } \mu \mathrm{W} \text { at } 20 \mathrm{~Hz}\end{array}$ & $\begin{array}{c}\text { Maximum } \\
\text { power } \\
\text { in } \mu \mathrm{W} \text { at } \\
30 \mathrm{~Hz}\end{array}$ \\
\hline PEH-A & 1570 & 872 & 120 & 19 \\
PEH-B & 814 & 441 & 225 & 43 \\
PEH-C & 547 & 312 & 276 & 72 \\
PEH-D & 362 & 164 & 202 & 106 \\
PEH-E & 175 & 158 & 189 & 146 \\
\hline
\end{tabular}

the vibration frequency is lower. Hence, it is understood that the harvested energy can be larger in weaker structures or damaged structures. However, when the vibration frequencies are higher (healthy structures) the harvested power is decreased. The other point is that the harvesters whose first resonant frequencies are closer to the frequency of vibration produces the maximum energy. These are the reasons for device $\mathrm{PEH}-\mathrm{C}$ to produce the maximum power at $20 \mathrm{~Hz}$ vibrations. Similarly device $\mathrm{PEH}-\mathrm{E}$ produces the maximum energy at $30 \mathrm{~Hz}$ vibrations. The fall in the power harvested at high frequencies is due to the fall in induced voltages. This analysis therefore clearly indicates that the resonant frequencies of the harvester array should be always less than the fundamental frequency of the structure in healthy condition for maximum energy harvesting.

4.4.2. Power Analysis at Different Vibration Frequencies. In this section, the performance of the energy harvesters is individually assessed for different vibration frequencies. Each harvester is connected to the load $R_{L}$ at which maximum power transfer occurs. These values of $R_{L}$ are obtained from 


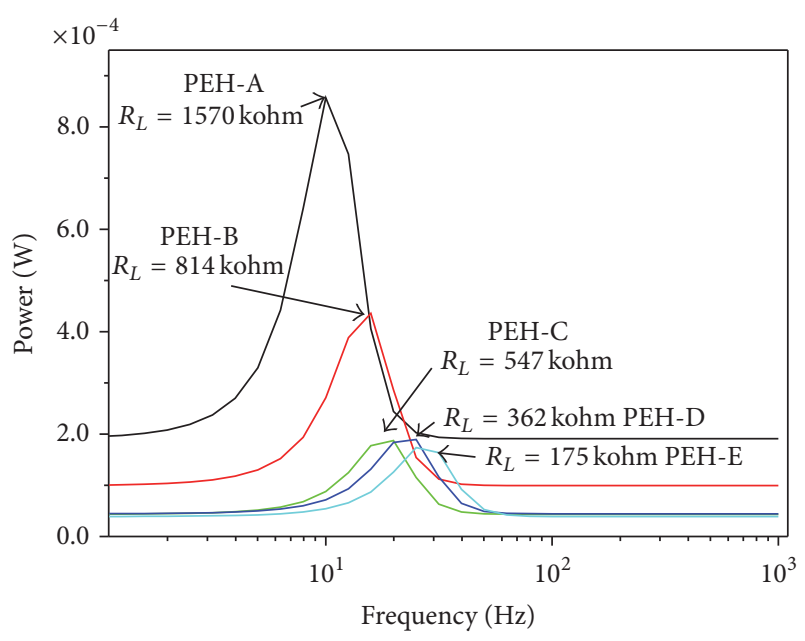

FIgURE 11: The OrCAD circuit configuration that is used to get these curves.

the results described in Figure 10. The results thus obtained are plotted against frequencies as shown in Figure 11.

4.4.3. Parallel Connection of Power Harvesters for Boosting Power Generation. As indicated in the earlier sections of this paper, the main aim of this research is to generate power for wireless transmission of SHM accelerometer picked up signal to a remote location. Five different power harvesters were designed with closely separated natural frequencies $(10 \mathrm{~Hz}-30 \mathrm{~Hz})$ so that required power generation takes place irrespective of the health condition of the civil structure under monitor. In this study, it is assumed that the civil structure under monitor has a fundamental frequency $30 \mathrm{~Hz}$ under healthy condition. Hence, these five sources are now connected in parallel to maximize the power output as shown in Figure 12.

In order to examine the configuration for which maximum power harvesting occurs, the number of sources connected in parallel configuration is gradually increased. The harvested powers at various load resistances are obtained assuming the frequency of vibration to be $10 \mathrm{~Hz}$. The results thus obtained are plotted against the load $\left(R_{L}\right)$ as shown in Figure 13. The peak power thus obtained in each case and the resistance at which this occurs are tabulated as given in Table 8 . The result clearly shows that the maximum power of $1.316 \mathrm{~mW}$ is harvested when harvesters $\mathrm{PEH}-\mathrm{A}, \mathrm{PEH}-\mathrm{B}$, and $\mathrm{PEH}-\mathrm{C}$ are connected in parallel. This is $50.91 \%$ improvement compared with the power generated by harvester PEHA alone. Therefore, it is clear that the accelerometer and energy harvester array design proposed in this work can considerably improve the energy harvested for wireless SHM applications. However, the power generated reduces as the fourth and fifth harvesters are connected in parallel. The reason behind this is the drastic fall in the generated voltage in PEH-D and PEH-E.

In order to verify this observation, the behavior of this array is studied for vibrations at $20 \mathrm{~Hz}$ and $30 \mathrm{~Hz}$. The results are presented in Figures 14 and 15. Once again it is very clear from these results that the power harvested at higher frequencies is less than that is harvested at lower frequencies. The lower voltage induced in the higher frequencies of vibration is the preliminary reason behind this performance degradation. Hence, the highest resonant frequency of the harvester array should be as minimum as possible and it should be limited to the natural frequency of the structure under monitor in healthy condition.

A closer look at the summarized results presented in Table 8 shows that the power harvested at $30 \mathrm{~Hz}$ (i.e., at the virgin condition of the beam) is very poor. However, the power generated at $10 \mathrm{~Hz}$ (damaged condition of the bridge) is quite considerable. This happens due to the fall in voltage generated at $30 \mathrm{~Hz}$ vibrations. In order to alleviate this problem, the design is modified as explained in the next section.

4.4.4. Modified Harvester Array Design. The various analyses in the previous section clearly show that the parallel configuration of all the five energy harvesters results in poor power output compared with the case in which the first three (PEH-A, PEH-B, and $\mathrm{PEH}-\mathrm{C}$ ) are connected in parallel. A deep look at the results shows that this is due to the poor voltage induced in the harvesters PEH-D and $\mathrm{PEH}-$ E. This happens due to wider frequency range $(10 \mathrm{~Hz}$ to $30 \mathrm{~Hz}$ ). In order to alleviate this problem the authors have restricted the resonant frequency ranges of the harvesters from $30 \mathrm{~Hz}-10 \mathrm{~Hz}$ to $20 \mathrm{~Hz}-10 \mathrm{~Hz}$. This section analyses the design of power harvester array from the five different natural frequencies to realize the range of 10 to $20 \mathrm{~Hz}$. The geometrics of the five new harvesters $\mathrm{PEH}-\mathrm{A}_{1}$ to $\mathrm{PEH}-\mathrm{E}_{1}$ are summarized in Table 9.

This section analyses the power harvested from these five different energy harvesters independently at various loads. The equivalent circuit of each harvester is used to estimate the power harvested at various load conditions. The equivalent circuit parameters of these devices estimated and used in the analyses are summarized in Table 10. OrCAD circuit simulator has been used for this purpose. The corresponding independent power output of the energy harvesters for vibration at $10 \mathrm{~Hz}$ frequency has been shown in Figure 16. Subsequently, the energy harvested when these five devices $\left(\mathrm{PEH}-\mathrm{A}_{1}\right.$ to $\left.\mathrm{PEH}-\mathrm{E}_{1}\right)$ are connected in parallel is plotted as shown in Figure 17. The maximum power outputs for different configuration are summarized in Table 11. The summary of the results clearly indicates that it is possible to harvest a power of $2.283 \mathrm{~mW}$ at $1 \mathrm{~g}$ vibration when all the five harvesters are operated in parallel configuration. Continuous flow of vehicles would be able to charge the batteries from the energy harvested from this arrangement to generate $25 \mathrm{~mW}$ [55] of power for transmission purposes in wireless SHM.

\section{Design and Simulation Studies on Piezoelectric Accelerometer}

The design and performance analysis of energy harvester array for charging the batteries in the wireless SHM mode has been discussed in detail in the previous sections. This section deals with the design and performance analysis of 


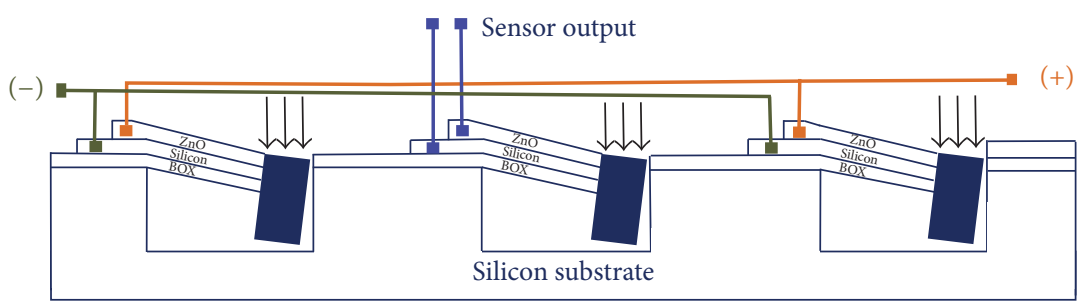

Figure 12: Parallel addition configuration for maximum harvesting with different frequencies.

TABLE 8: Power output at $g=1$ for parallel connected energy harvesters.

\begin{tabular}{lcccc}
\hline Harvester configuration & $\begin{array}{r}R_{L} \text { at peak power } \\
\text { in } \mathrm{k} \Omega\end{array}$ & $\begin{array}{c}\text { Maximum power } \\
\text { in } \mu \mathrm{W} \text { at } 10 \mathrm{~Hz}\end{array}$ & $\begin{array}{c}\text { Maximum power } \\
\text { in } \mu \mathrm{W} \text { at } 20 \mathrm{~Hz}\end{array}$ & $\begin{array}{c}\text { Maximum power } \\
\text { in } \mu \mathrm{W} \text { at } 30 \mathrm{~Hz}\end{array}$ \\
\hline $\mathrm{A}$ & 1570 & 872 & 120.05 & 19.36 \\
$\mathrm{~A} \| \mathrm{B}$ & 525 & 1171 & 345.83 & 62.71 \\
$\mathrm{~A}\|\mathrm{~B}\| \mathrm{C}$ & 350 & 1316 & 685.53 & 132.14 \\
$\mathrm{~A}\|\mathrm{~B}\| \mathrm{C} \| \mathrm{D}$ & 175 & 1267 & 753.33 & 239.29 \\
$\mathrm{~A}\|\mathrm{~B}\| \mathrm{C}\|\mathrm{D}\| \mathrm{E}$ & 175 & 1135 & 753.33 & 239.29 \\
\hline
\end{tabular}

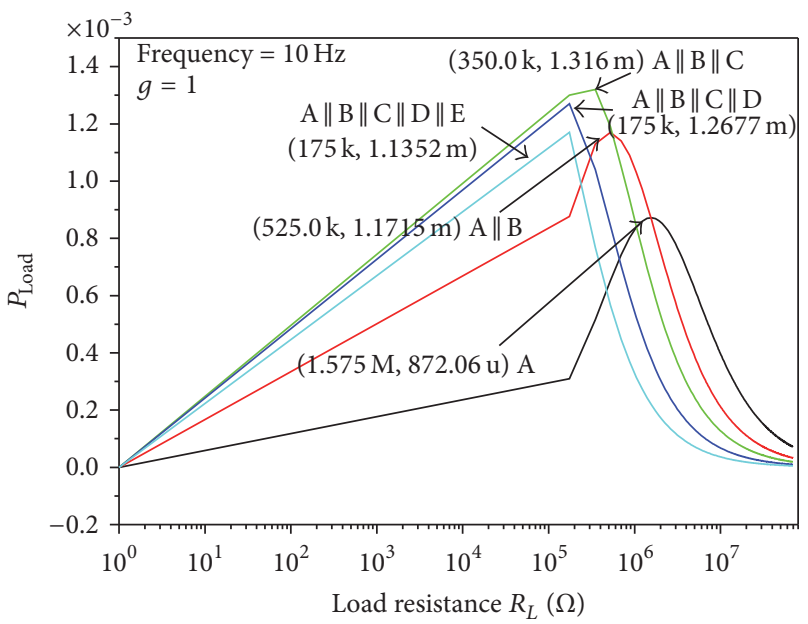

FIGURE 13: Output power for parallel connection of energy harvesters for $g=1$ at $10 \mathrm{~Hz}$.

the micro accelerometer integrated along with the energy harvester array for picking up the vibration signals. This section gives the design and analysis of such an accelerometer using a cantilever beam structure. The structure has been created using COMSOL Multiphysics simulation tool and the various performances indicating factors were estimated by displacement studies, voltage studies, charge sensitivity studies, modal analysis, stress analysis, frequency response analysis, noise analysis, and cross-axis sensitivity analysis. The details of these performance analyses and the results of these analyses are also presented in this section.

5.1. Specifications and Design. The specifications of the proposed micro accelerometer integrated along with the energy harvester array for wireless SHM application are given in Table 12. These specifications are arrived at assuming that the

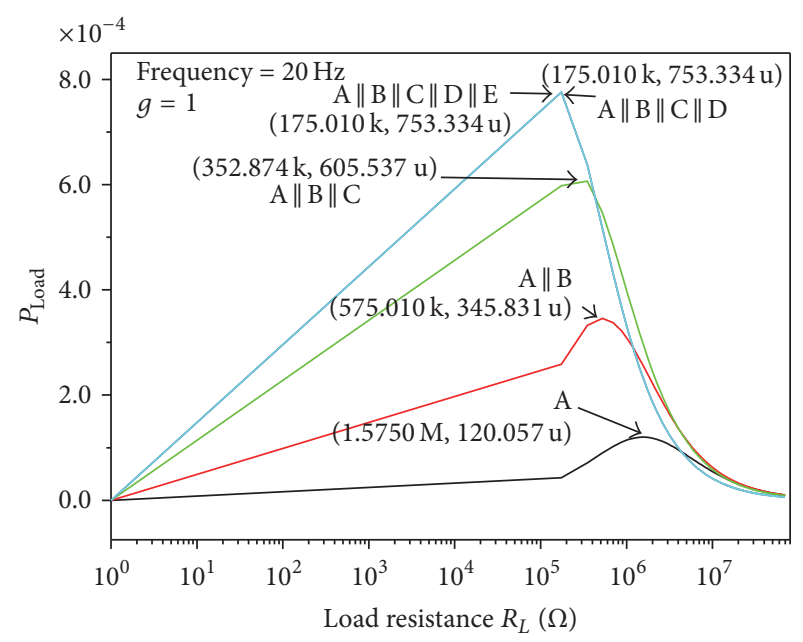

FIGURE 14: Output power for parallel connected energy harvesters for vibration at $20 \mathrm{~Hz}$.

bridge under monitor has a resonant frequency of $20 \mathrm{~Hz}$ at healthy condition.

A closer look at these specifications and Table 9 shows that it is possible to use device $\mathrm{PEH}-\mathrm{E}_{1}$ itself to achieve the design specification given in Table 12.

5.2. Displacement Studies. The structure was created in COMSOL Multiphysics with the usual settings and boundary conditions as briefed in Section 3.4. The measured deflections at various acceleration in the range of 0 to $2 \mathrm{~g}$ have been obtained through COMSOL Multiphysics simulation tool. The temperature is fixed at $20^{\circ} \mathrm{C}$. The deflection versus acceleration graph as shown in Figure 18 gives the measured deflection at various accelerations obtained from simulation experiments. The deflection sensitivity is estimated by finding the slope of the deflection versus acceleration curve as shown 
TABLE 9: Geometrics of the energy harvesters.

\begin{tabular}{|c|c|c|c|c|c|c|}
\hline Beam model & $\begin{array}{l}\text { Length } \\
\left(L_{b}\right) \text { in } \mathrm{mm}\end{array}$ & $\begin{array}{l}\text { Length of the mass } \\
\left(L_{m}\right) \text { in } \mathrm{mm}\end{array}$ & $\begin{array}{c}\text { Beam } \\
\text { width }\left(W_{b}\right) \text { in } \mu \mathrm{m}\end{array}$ & $\begin{array}{l}\text { Thickness of the } \\
\text { piezoelectric } \\
\text { layer }\left(t_{p}\right) \text { in } \mu \mathrm{m}\end{array}$ & $\begin{array}{l}\text { Thickness of the silicon } \\
\text { layer }\left(t_{s}\right) \text { in } \mu \mathrm{m}\end{array}$ & $\begin{array}{c}\text { Natural } \\
\text { frequency in } \mathrm{Hz}\end{array}$ \\
\hline PEH-A & 20 & 15 & 1000 & 45 & 50 & 10.94 \\
\hline PEH-B & 20 & 15 & 1200 & 45 & 50 & 12.49 \\
\hline $\mathrm{PEH}-\mathrm{C}_{1}$ & 20 & 15 & 2000 & 45 & 50 & 15 \\
\hline PEH-D 1 & 20 & 15 & 2500 & 45 & 50 & 17.5 \\
\hline $\mathrm{PEH}-\mathrm{E}_{1}$ & 20 & 15 & 3000 & 45 & 50 & 20 \\
\hline
\end{tabular}

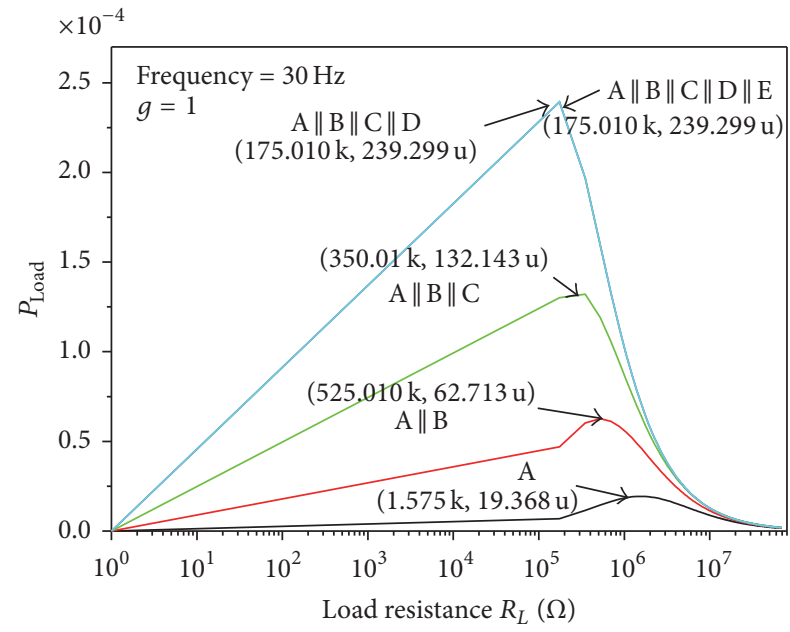

FIGURE 15: Output power for parallel connected energy harvesters for vibration at $30 \mathrm{~Hz}$.

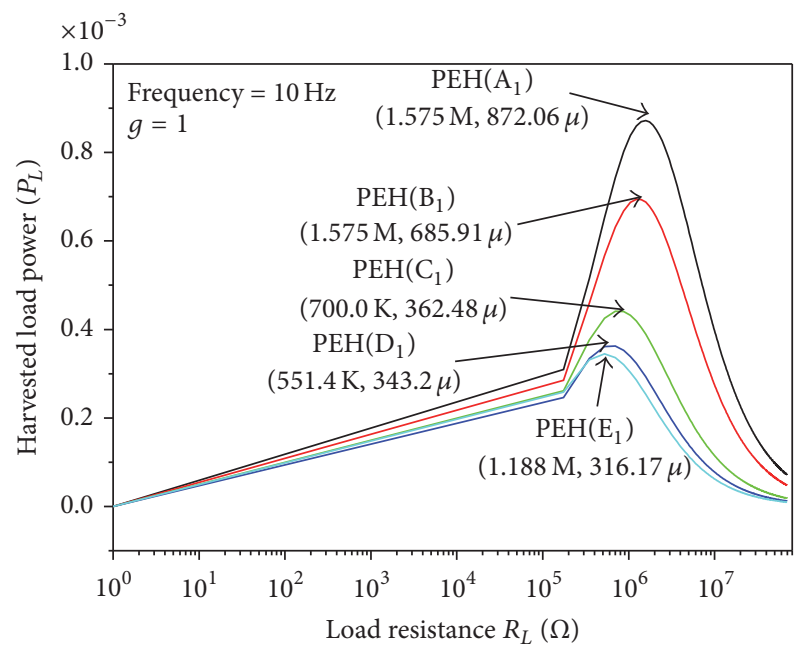

FIGURE 16: Output power of the energy harvester PEH-A to PEH$\mathrm{E}_{1}$ at various loads at frequency $10 \mathrm{~Hz}$.

in Figure 18. The maximum deflection measured at $2 \mathrm{~g}$ is $1369.4 \mu \mathrm{m}$ and it is seen. It corresponds to a sensitivity of $684.7 \mu \mathrm{m} / \mathrm{g}$.

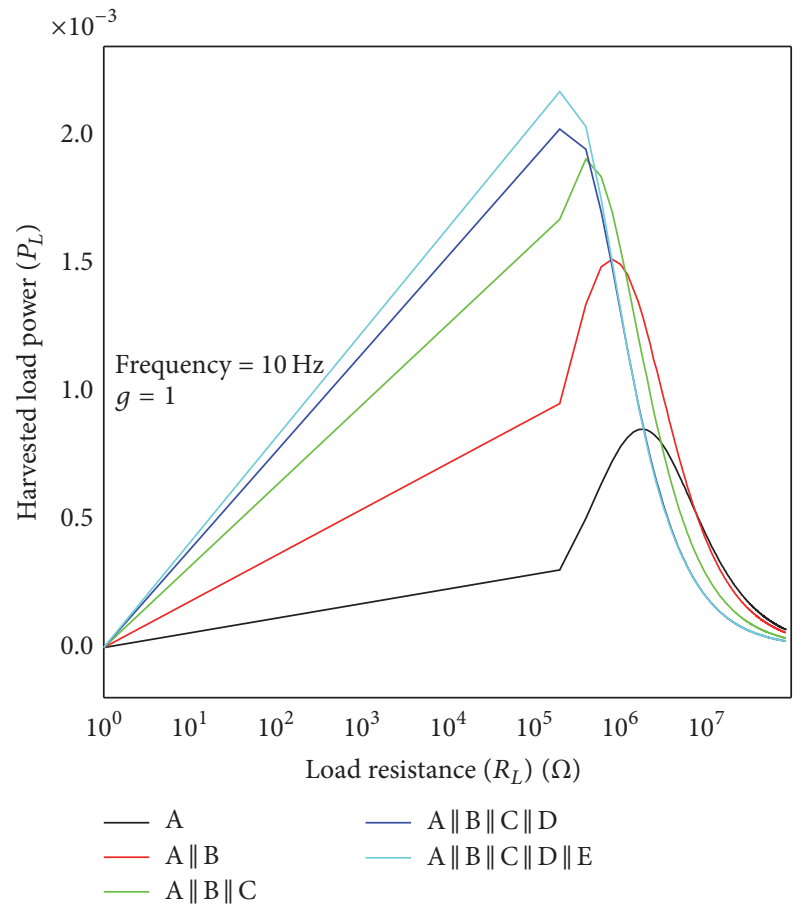

FIGURE 17: Output power for parallel connected energy harvesters for vibration at $10 \mathrm{~Hz}$.

TABLE 10: Equivalent circuit parameters of the energy harvester.

\begin{tabular}{lccc}
\hline Model & $\begin{array}{c}\text { Resistance } \\
\left(R_{p}\right) \text { in } \mathrm{M} \Omega\end{array}$ & $\begin{array}{c}\text { Capacitance } \\
\left(C_{p}\right) \text { in } \mathrm{pF}\end{array}$ & $\begin{array}{c}\text { Voltage } \\
\text { at 10 Hz in volts }\end{array}$ \\
\hline PEH-A $_{1}$ & 1.685 & 40.16 & 72.07 \\
PEH-B $_{1}$ & 1.406 & 48.78 & 58.67 \\
PEH-C $_{1}$ & 843 & 80.30 & 36.30 \\
PEH-D $_{1}$ & 675 & 100.20 & 29.46 \\
PEH-E $_{1}$ & 560 & 120.40 & 26.13 \\
\hline
\end{tabular}

5.3. Voltage Studies. The peak voltage induced in piezoelectric accelerometers integrated with energy harvester array is obtained at various acceleration levels by piezoelectric simulation in the COMSOL environment. The value of induced peak voltage thus obtained is plotted against acceleration as given in Figure 19. As it is expected, the induced peak voltage linearly varies with acceleration and the measured induced peak voltage at $2 \mathrm{~g}$ by simulation is $55.35 \mathrm{~V}$. It corresponds to 


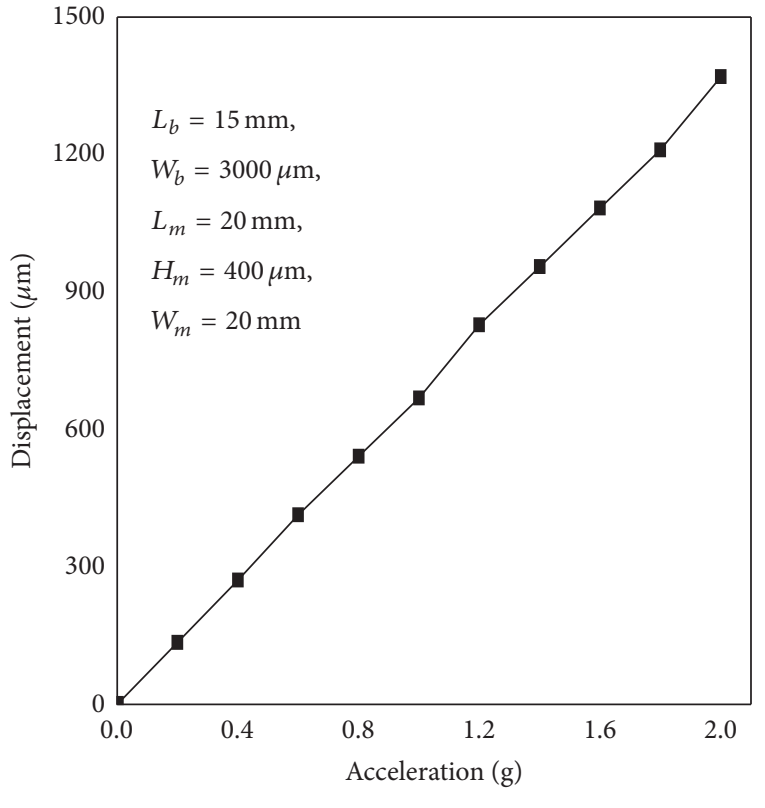

FIGURE 18: Tip deflection of the piezoelectric cantilever beam against acceleration.

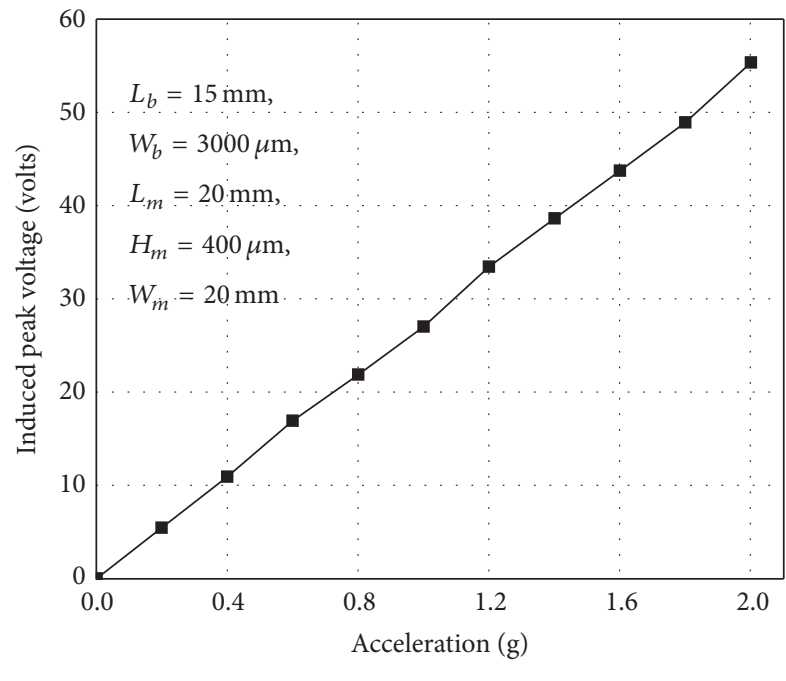

FIGURE 19: Induced peak voltage for $L_{b}=15 \mathrm{~mm}, W_{b}=3000 \mu \mathrm{m}$, $L_{m}=20 \mathrm{~mm}, H_{m}=400 \mu \mathrm{m}$, and $W_{m}=20 \mathrm{~mm}$ as compared with COMSOL Multiphysics simulation and modeling by varying the gravity $(0-2 \mathrm{~g})$.

$27.67 \mathrm{~V} / \mathrm{g}$ voltage sensitivity. This is very high compared with the accelerometers using piezoelectric and capacitive sensing techniques.

5.4. Charge Sensitivity Studies. The charge sensitivity of the proposed device for various acceleration levels has been obtained by using (29) and it has been plotted against the acceleration (gravity) as shown in Figure 20.

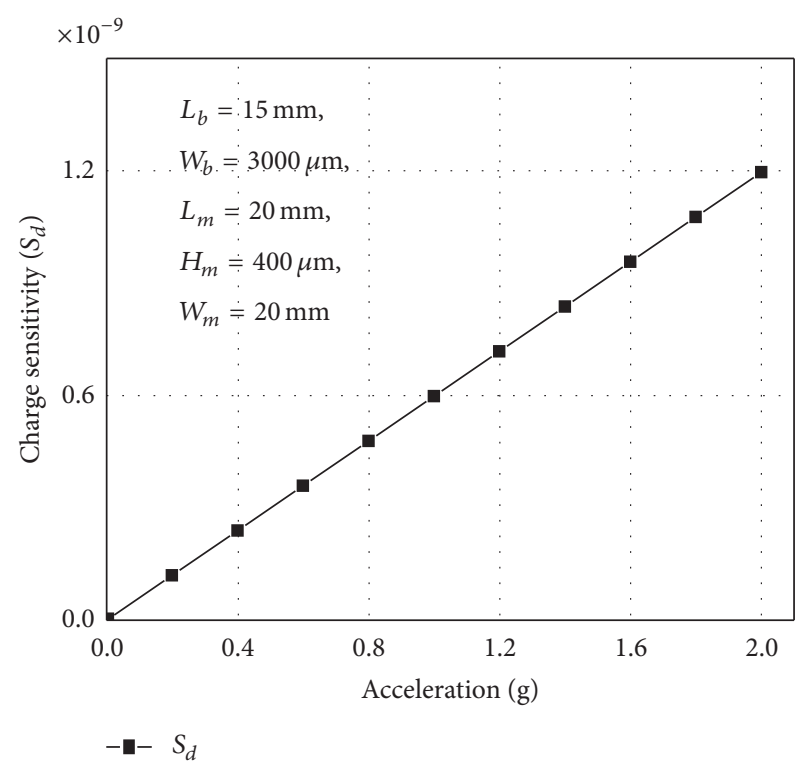

FIGURE 20: Charge sensitivity for various gravity.

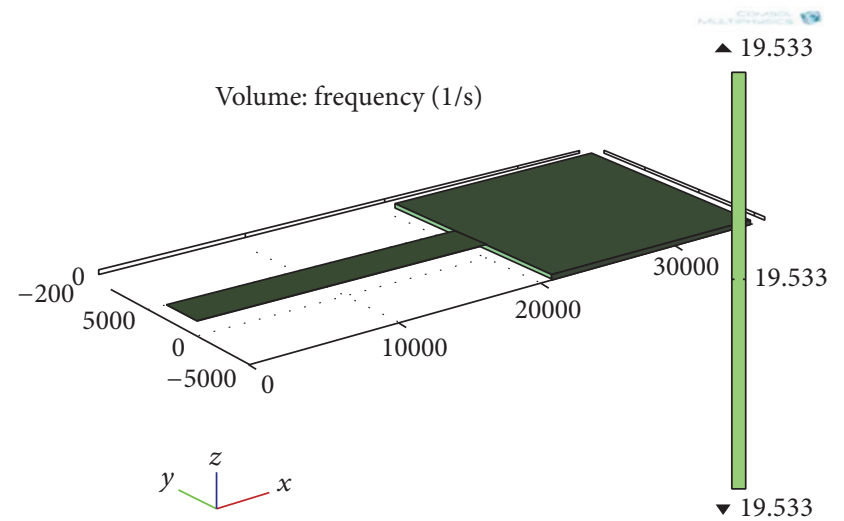

FIGURE 21: Simulation result of modal frequency of device PEH-E using COMSOL Multiphysics.

TABLE 11: Power output at $g=1$ for parallel connected energy harvesters.

\begin{tabular}{lcc}
\hline Component & $\begin{array}{c}R_{L} \text { at peak power } \\
\text { in } \mathrm{k} \Omega\end{array}$ & $\begin{array}{c}\text { Maximum power } \\
\text { in } \mu \mathrm{W} \text { at } 10 \mathrm{~Hz}\end{array}$ \\
\hline $\mathrm{A}_{1} \| \mathrm{B}_{1}$ & 1570 & 872 \\
$\mathrm{~A}_{1} \| \mathrm{B}_{1}$ & 742 & 1543 \\
$\mathrm{~A}_{1}\left\|\mathrm{~B}_{1}\right\| \mathrm{C}_{1}$ & 396 & 1830 \\
$\mathrm{~A}_{1}\left\|\mathrm{~B}_{1}\right\| \mathrm{C}_{1} \| \mathrm{D}_{1}$ & 184 & 2041 \\
$\mathrm{~A}_{1}\left\|\mathrm{~B}_{1}\right\| \mathrm{C}_{1}\left\|\mathrm{D}_{1}\right\| \mathrm{E}_{1}$ & 181 & 2283 \\
\hline
\end{tabular}

The charge sensitivity obtained for this device is quite high compared with the reported results in the literature.

5.5. Modal Analysis. The vibration mode analysis was also conducted by COMSOL Multiphysics simulation tool. The first three mode natural frequencies of piezoelectric micro accelerometer integrated along with the energy harvester array obtained through the simulation can be seen in Figure 21 and the values are listed in Table 13. The first mode 


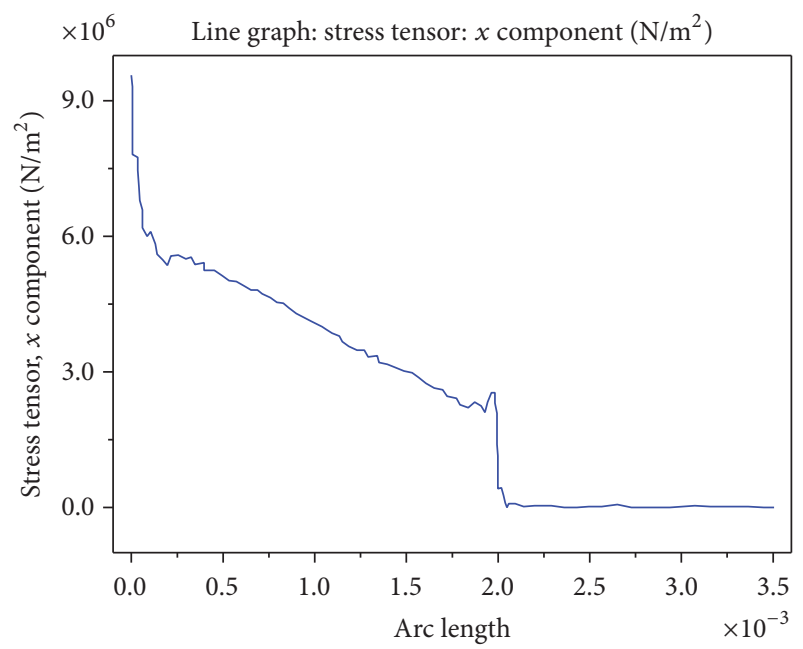

(a)

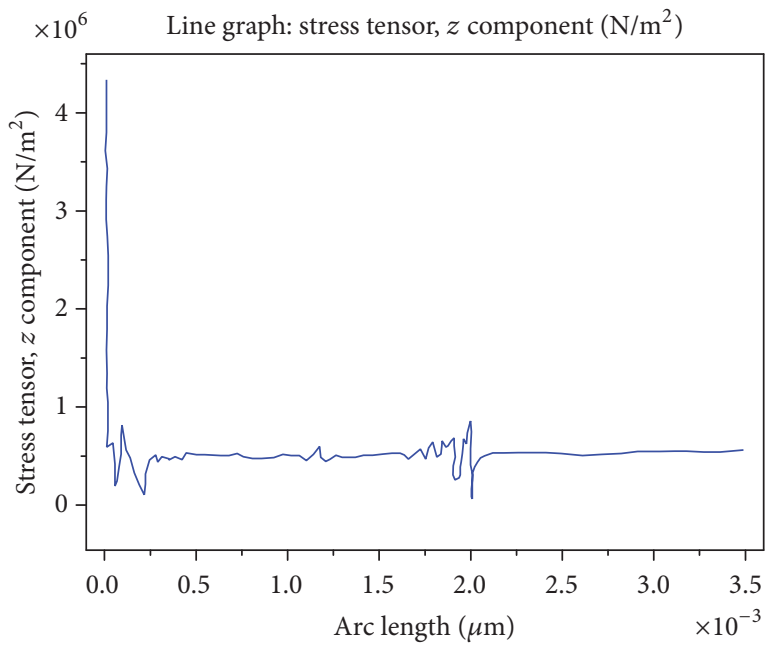

(c)

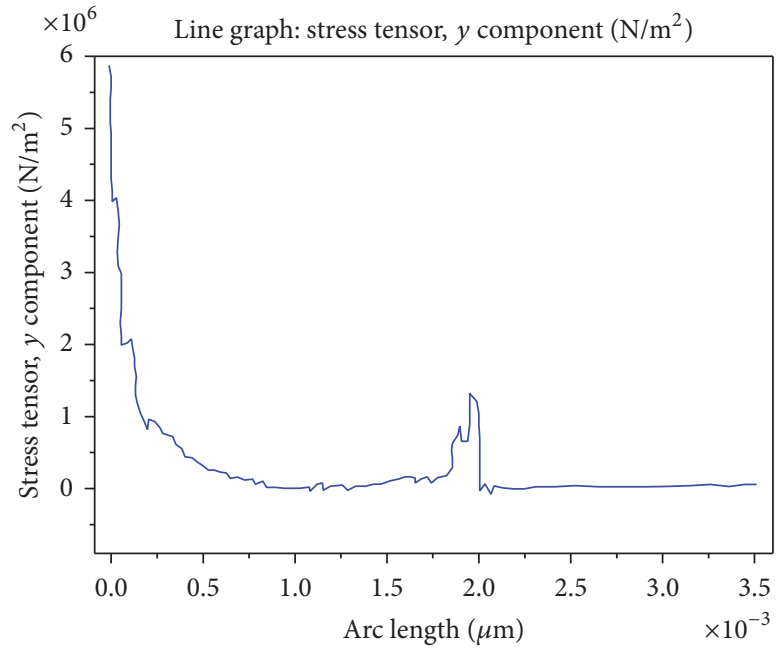

(b)

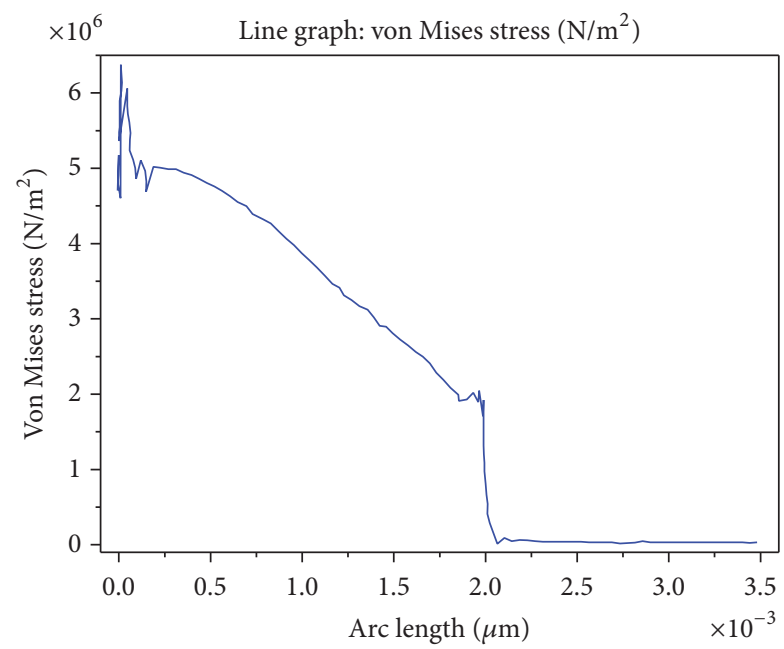

(d)

Figure 22: (a) Stress $\left(S_{x}\right)\left(\mathrm{N} / \mathrm{m}^{2}\right)$ obtained using COMSOL Multiphysics simulation at $2 \mathrm{~g}$. (b) Stress $\left(S_{y}\right)\left(\mathrm{N} / \mathrm{m}^{2}\right)$ obtained using COMSOL Multiphysics simulation at $2 \mathrm{~g}$. (c) Stress $\left(S_{z}\right)\left(\mathrm{N} / \mathrm{m}^{2}\right)$ obtained using COMSOL Multiphysics simulation at $2 \mathrm{~g}$. (d) Von Mises stress $\left(\mathrm{N} / \mathrm{m}^{2}\right)$.

TABLE 12: Specification of the micro accelerometer integrated along with the energy harvester.

\begin{tabular}{lc}
\hline Parameter & Specified value \\
\hline Acceleration range & $0-2 \mathrm{~g}$ \\
Resonance (bandwidth) & $20 \mathrm{~Hz}$ \\
Cross-axis sensitivity & $<5 \%$ \\
Noise floor & $<10 \mathrm{ng} / \sqrt{\mathrm{Hz}}$ \\
\hline
\end{tabular}

frequency obtained through simulation is $19.53 \mathrm{~Hz}$ against the design value of $20 \mathrm{~Hz}$ and this value closely matches theoretical natural frequency.

5.6. Stress Analysis. Successful implementation of piezoelectric accelerometers needs to achieve high stress induction
TABLE 13: Modal frequencies.

\begin{tabular}{lccc}
\hline Device & \multicolumn{3}{c}{$\begin{array}{c}\text { Modal frequencies in } \mathrm{Hz} \\
\text { Mode 2 }\end{array}$} \\
\hline PEH-E 1 & 19.53 & 102.60 & Mode 3 \\
\hline
\end{tabular}

so that large voltage is induced. However, these stress levels should not harm the structure physically. Hence stress analyses were conducted using COMSOL simulation. In this analysis, the acceleration was applied in all the three axes $(x-$, $y$-, and $z$-axes) and corresponding developed stresses on the cantilever beam have been obtained. The stress levels $(x-, y$-, and $z$-axes) in all the three axes experienced by the beam at $+2 \mathrm{~g}$ for proposed device are plotted against the various positions along $x$-axis to the beam as shown in Figures 22(a), 


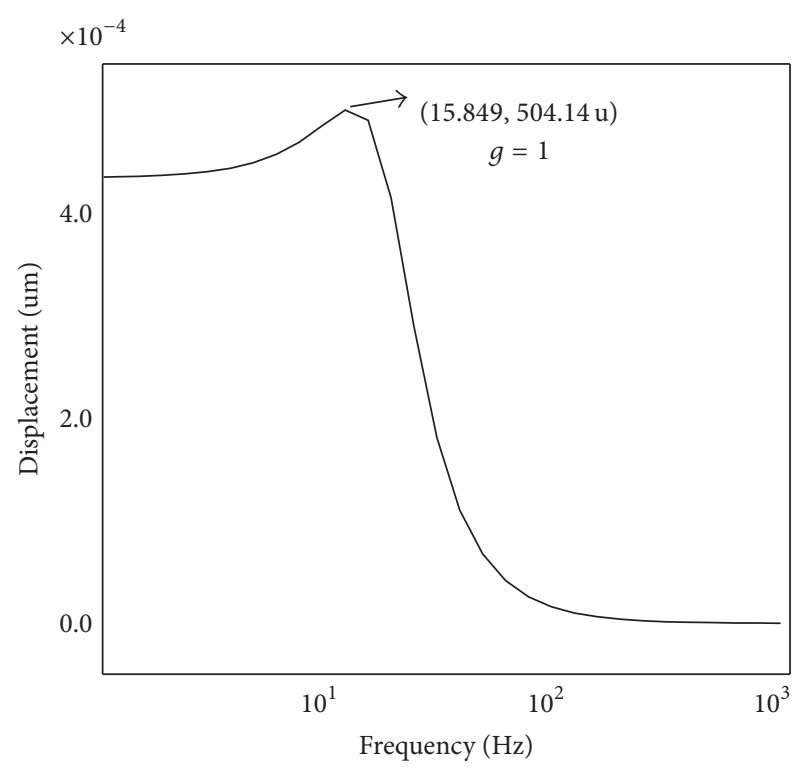

FIGURE 23: Frequency versus displacement analysis of the device at $1 \mathrm{~g}$.

22(b), and 22(c), respectively, and Figure 22(d) shows the Von Mises stress developed in the beam.

These results clearly show that the stress levels are well within limits and would not cause any physical damage when the acceleration is within $2 \mathrm{~g}$.

5.7. Frequency Analysis. The piezoelectric micro accelerometer integrated along with the energy harvester array for wireless SHM application needs less than $50 \mathrm{~Hz}$ band width and therefore it is a favorable situation and low frequency design should result in an ideal sensor for wireless SHM applications compared with the COTS (commercial off-theshelf) accelerometers. In order to validate this argument, the frequency response of the proposed device has been obtained using OrCAD software that is described in Section 4.3.

The accelerometer structure adopted in this research obeys a second-order differential equation and the frequency response of this system can be written as

$$
\delta=\frac{F / k}{\sqrt{\left[1-\left(f^{2} / f_{0}^{2}\right)\right]^{2}+\left[2 \xi\left(f / f_{0}\right)\right]^{2}}},
$$

where the $\xi=b / b_{c}$ is the critical damping factor and $F, f$, and $f_{0}$ are the applied force, the frequency for which $\delta$ is estimated, and the resonant frequency, respectively.

The frequency response of proposed device for damping coefficient $\xi=0.5$ has been calculated using (43) and plotted as shown in Figure 23. It is evident from the graph that the deflection sensitivity is considerably increased when the resonant frequency of the sensor or band width is reduced. In the present case, the proposed device gives deflection sensitivity of $580.142 \mu \mathrm{m} / \mathrm{g}$ at $15.84 \mathrm{~Hz}$ bandwidth.

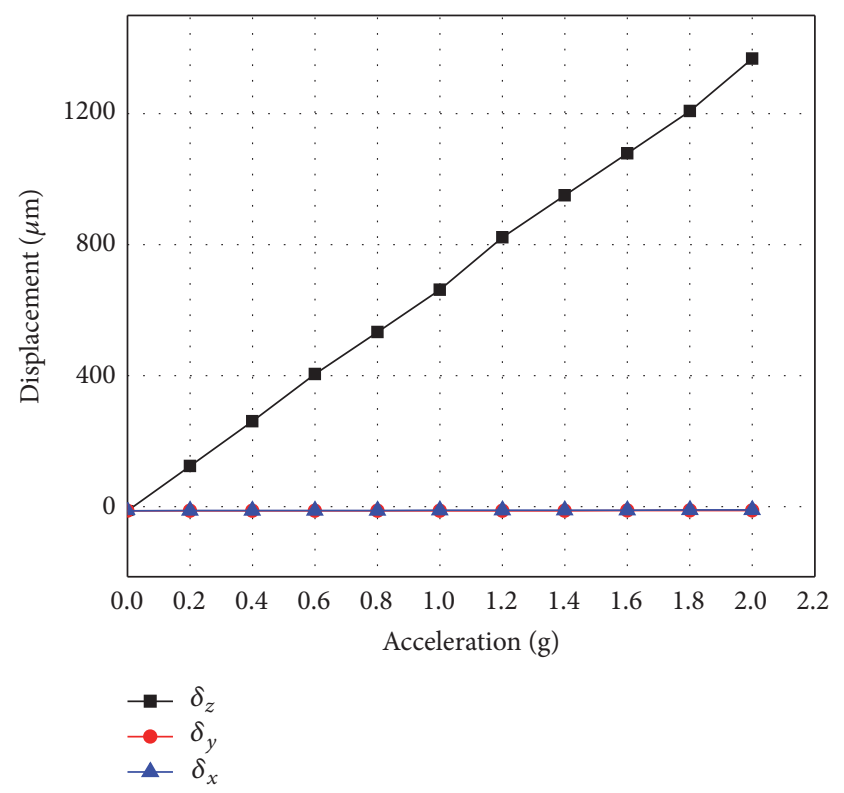

FIgURE 24: Comparison of cross-axis displacement for devices' ranges at gravity $0-2 \mathrm{~g}$.

5.8. Noise Analysis and Results. The accelerometer sensor noise floor is usually dominated by the deflection noise, but in micromechanical systems it is often set by the thermomechanical noise or Brownian noise [25]. The noise arises from the thermal motion of the atoms inside the structure and in the surrounding air and is a temperature-dependent parameter. The exact value of the damping need not to be computed and can be asserted with the quality factor of the system under harmonic excitation. Thus, the thermal noise displacement for a damped accelerometer outside the resonance $\left(f_{0}\right)$ is given by [25]

$$
x_{t m}=\sqrt{\frac{8 K_{B} T \omega_{0} \xi}{m}} \mathrm{~g} / \sqrt{\mathrm{Hz}},
$$

where $m$ is the mass of the seismic block and $\xi$ is the damping factor. This thermomechanical displacement is found to be $12.221 \mathrm{ng} / \sqrt{\mathrm{Hz}}$. This corresponds to a total noise voltage $\left(v_{t m}\right)$ of $348.13 \mathrm{nV} / \sqrt{\mathrm{Hz}}$. The resolution of an accelerometer determines the minimum acceleration that can be measured. The resolution is the ratio between the total noise voltage divided by the voltage sensitivity $\left(S_{v}\right)$ and it can be written as [25]

$$
r=\frac{V_{n t}}{S_{v}} .
$$

The resolution of the device is estimated to be $54.62 \mathrm{ng}$ and when it is designed to measure a maximum acceleration of $2 \mathrm{~g}$. These small noise floor and high resolution achieved for the proposed device definitely satisfy the requirements for wireless SHM application.

5.9. Cross-Axis Sensitivity. In order to evaluate the cross-axis performance of piezoelectric micro accelerometer integrated 


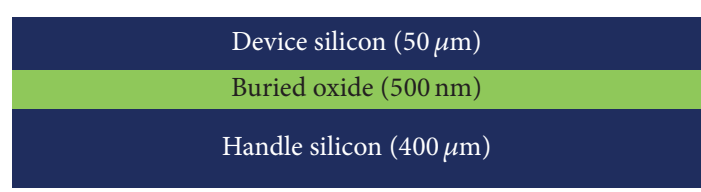

(a) RCA cleaning

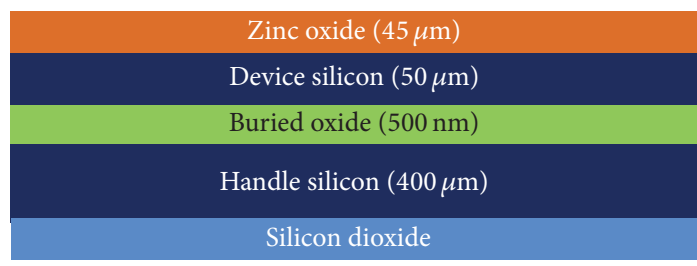

(c) $\mathrm{ZnO}$ film formation

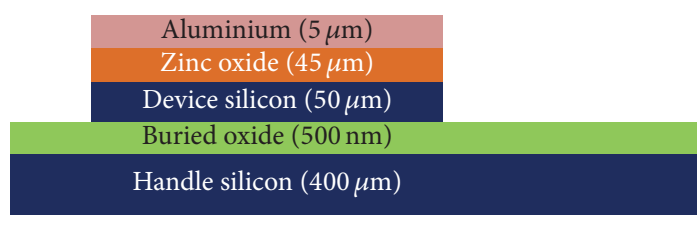

(e) Patterning $\mathrm{ZnO}$, aluminium, and device silicon

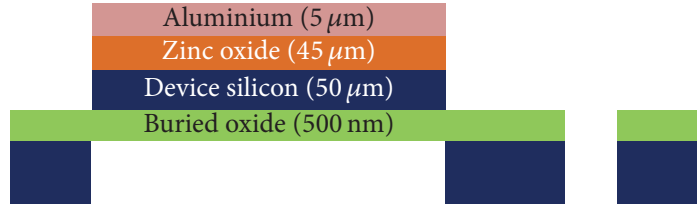

(g) Back etching by DRIE to realize cantilever beam mass

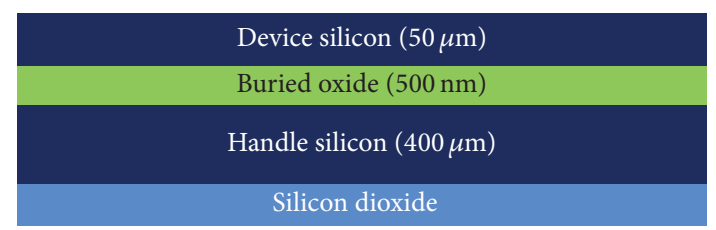

(b) Wet oxidation and top oxide removal

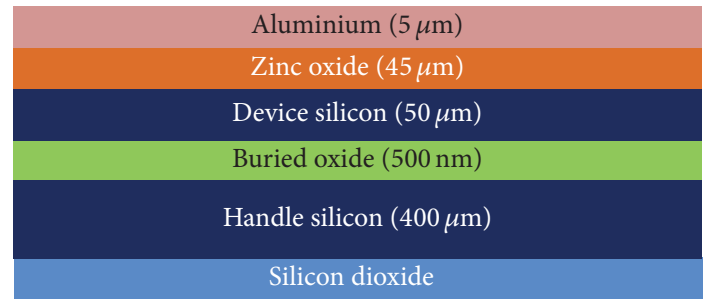

(d) Aluminium deposition

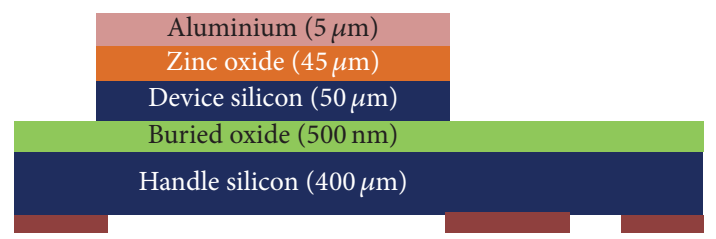

(f) $\mathrm{SiO}_{2}$ patterning for back etching

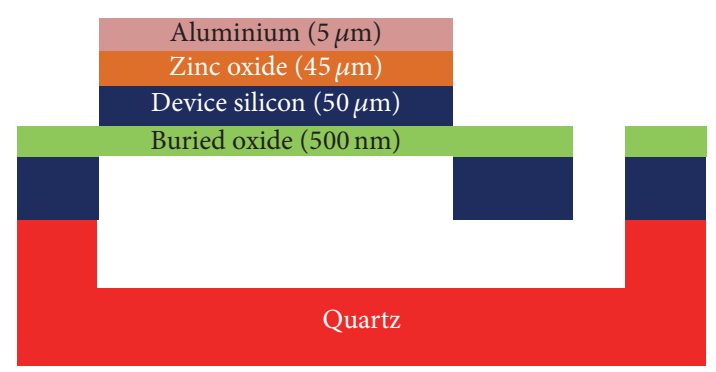

(h) Packaged device

FIGURE 25: Fabrication process steps (not to scale).

along with energy harvester array using a cantilever beam with a suspended mass, acceleration was applied in all the directions and the corresponding displacements at various $\mathrm{g}$ are plotted in Figure 24. From Figure 24, it is known that this piezoelectric micro accelerometer integrated along with energy harvester array has single-axis performance ( $z$-axis). It is evident from Figure 24 that the main axis sensitivity is high compared with the other axes' sensitivity, thus demonstrating the ability of this structure to offer the best the cross-axis performance.

\section{Fabrication Process Steps}

The fabrication process flow of the energy harvester array integrated with micro accelerometer is diagrammed in Figure 25. Silicon-on-Insulator wafer with a handle silicon thickness of $400 \mu \mathrm{m}$ and a device silicon thickness as required (equal to the substrate layer thickness) are RCA cleaned first. $\mathrm{ZnO}$ film sputtering and aluminium deposition are the next two process steps. The $\mathrm{ZnO}$ forms the piezoelectric layer and the aluminium film acts as the top electrode.
Alternatively $\mathrm{ZnO}$ film can be prepared and spin-on coated on SoI substrates at $3000 \mathrm{rpm}$ for $20 \mathrm{sec}$, followed by pyrolysis at $300^{\circ} \mathrm{C}$ for $2 \mathrm{~min}$. This is followed by the patterning and etching of aluminium, $\mathrm{ZnO}$, and device silicon layer to form the cantilever beam. Finally, the handle silicon is back etched by DRIE to realize the bulk mass at the free end of the cantilever beam. Packaging is performed cast.

\section{Conclusion}

In this paper, the authors report the feasibility of fabricating an energy harvester integrated sensor node. Low frequency design and parallel operation of multifrequency energy harvesters have been attempted to achieve high performance energy harvesting. The novelty of this design lies in the fact that the energy harvesters have their natural frequencies chosen less than the natural frequency of the structure in the healthy condition. This enables high power generation even with the onset of damage in the structure, thus ensuring reliable power supply and data transfer with progression of damage of the structure under monitor. Such a design 
proposed and studied in this work shows that it is possible to harvest a power to the tune of $2.28 \mathrm{~mW} / \mathrm{g}$ at a load of $181 \mathrm{k} \Omega$. This is three orders more compared with similar energy harvesters found in the literature. It is also true that the power generated using this energy harvester array is approximately three times more than the power harvested by a single energy harvester. These results demonstrate that the multiple resonant frequency energy harvester when operated in parallel can effectively improve energy harvesting performance. Since the main objective of this work is to achieve energy harvester integrated with a sensor for vibration sensing, the authors have also designed and studied the performance of a piezoelectric accelerometer designed for low frequency vibration measurement. The accelerometer thus designed has a sensitivity of $27.67 \mathrm{~V} / \mathrm{g}$, noise floor of $0.348 \mu \mathrm{V} / \sqrt{\mathrm{Hz}}$, and a resolution of $54.62 \mathrm{ng}$. This performance makes this device ideal for bridge monitoring applications. Since piezoelectric mechanism is used, integration of energy harvester and accelerometer in a single chip has become possible.

Finally, this research work clearly demonstrates that it is possible to fabricate a high performance wireless sensor node integrated with the necessary energy harvesting electronics for bridge health monitoring applications.

\section{Competing Interests}

The authors declare that they have no competing interests.

\section{References}

[1] A. E. Badri, J. K. Sinha, and A. Albarbar, "A typical filter design to improve the measured signals from MEMS accelerometer," Measurement: Journal of the International Measurement Confederation, vol. 43, no. 10, pp. 1425-1430, 2010.

[2] A. C. Jeyasehar and K. Sumangala, "Nondestructive evaluation of prestressed concrete beams using an artificial neural network (ANN) approach," Structural Health Monitoring, vol. 5, no. 4, pp. 313-323, 2006.

[3] J. P. Lynch, A. Partridge, K. H. Law, T. W. Kenny, A. S. Kiremidjian, and E. Carryer, "Design of piezoresistive MEMSbased accelerometer for integration with wireless sensing unit for structural monitoring," Journal of Aerospace Engineering, vol. 16, no. 3, pp. 108-114, 2003.

[4] A. Vogl, D. T. Wang, P. Storås et al., "Design, process and characterisation of a high-performance vibration sensor for wireless condition monitoring," Sensors and Actuators, A: Physical, vol. 153, no. 2, pp. 155-161, 2009.

[5] A. Partridge, J. K. Reynolds, B. W. Chui et al., "A high-performance planar piezoresistive accelerometer," Journal of Microelectromechanical Systems, vol. 9, no. 1, pp. 58-66, 2000.

[6] Á. Kovács and Z. Vízváry, "Structural parameter sensitivity analysis of cantilever- and bridge-type accelerometers," Sensors and Actuators, A: Physical, vol. 89, no. 3, pp. 197-205, 2001.

[7] F. K. Shaikh and S. Zeadally, "Energy harvesting in wireless sensor networks: a comprehensive review," Renewable and Sustainable Energy Reviews, vol. 55, pp. 1041-1054, 2016.

[8] A. Hamdan, F. Mustapha, K. A. Ahmad, and A. S. Mohd Rafie, "A review on the micro energy harvester in Structural Health Monitoring (SHM) of biocomposite material for Vertical Axis Wind Turbine (VAWT) system: a Malaysia perspective,"
Renewable and Sustainable Energy Reviews, vol. 35, pp. 23-30, 2014.

[9] A. S. M. Z. Kausar, A. W. Reza, M. U. Saleh, and H. Ramiah, "Energizing wireless sensor networks by energy harvesting systems: scopes, challenges and approaches," Renewable and Sustainable Energy Reviews, vol. 38, pp. 973-989, 2014.

[10] F. U. Khan and M. Iqbal, "Electromagnetic-based bridge energy harvester using traffic-induced bridge's vibrations and ambient wind," in Proceedings of the International Conference on Intelligent Systems Engineering (ICISE '16), pp. 380-385, January 2016.

[11] R. Ge, H. Pan, Z. Lin, N. Gong, J. Wang, and X. Chen, "RFpowered battery-less Wireless Sensor Network in structural monitoring," in Proceedings of the IEEE International Conference on Electro Information Technology (EIT '16), pp. 547-552, Grand Forks, ND, USA, May 2016.

[12] K. J. Vinoy and T. V. Prabhakar, "A universal energy harvesting scheme for operating low-power wireless sensor nodes using multiple energy resources," in Micro and Smart Devices and Systems, Springer Tracts in Mechanical Engineering, pp. 453466, Springer, New Delhi, India, 2014.

[13] Y. Li and R. Shi, "An intelligent solar energy-harvesting system for wireless sensor networks," Eurasip Journal on Wireless Communications and Networking, vol. 2015, no. 1, article 179, pp. 1-12, 2015.

[14] Y. Yukun, Y. Zhilong, and W. Guan, "Clustering routing algorithm of self-energized wireless sensor networks based on solar energy harvesting," Journal of China Universities of Posts and Telecommunications, vol. 22, no. 4, pp. 66-73, 2015.

[15] C. Maruccio, G. Quaranta, L. D. Lorenzis, and G. Monti, "Energy harvesting from electrospun piezoelectric nanofibers for structural health monitoring of a cable-stayed bridge," Smart Materials and Structures, vol. 25, no. 8, Article ID 085040, 2016.

[16] Y. H. Seo, B.-H. Kim, and D.-S. Choi, "Piezoelectric micro power harvester using flow-induced vibration for intrastructure health monitoring applications," Microsystem Technologies, vol. 21, no. 1, pp. 169-172, 2013.

[17] J. J. McCullagh, T. Galchev, R. L. Peterson et al., "Long-term testing of a vibration harvesting system for the structural health monitoring of bridges," Sensors and Actuators, A: Physical, vol. 217, pp. 139-150, 2014.

[18] H.-H. Huang and K.-S. Chen, "Design, analysis, and experimental studies of a novel PVDF-based piezoelectric energy harvester with beating mechanisms," Sensors and Actuators, A: Physical, vol. 238, pp. 317-328, 2016.

[19] A. Alvarez-Carulla, J. Colomer-Farrarons, J. Lopez-Sanchez, and P. Miribel-Catala, "Piezoelectric harvester-based selfpowered adaptive circuit with wireless data transmission capability for structural health monitoring," in Proceedings of the Conference on Design of Circuits and Integrated Systems (DCIS '15), Estoril, Portugal, November 2015.

[20] C. Mo and J. Davidson, "Energy harvesting technologies for structural health monitoring applications," in Proceedings of the 1st IEEE Conference on Technologies for Sustainability (SusTech '13), pp. 192-198, August 2013.

[21] M. Antunes Galhardi, T. H. Guilherme, and V. L. Junior, "A review of power harvesting from vibration using piezo electric materials and applications," in Proceedings of the 7th Brazilian Conference on Dynamics, Control and Applications, São Paulo, Brasil, 2008.

[22] S. M. Taware and S. P. Deshmukh, "A review of energy harvesting from piezoelectric materials," IOSR Journal of Mechanical and Civil Engineering (IOSR-JMCE), pp. 43-50, 2013. 
[23] S. Roundy, P. K. Wright, and J. Rabaey, "A study of low level vibrations as a power source for wireless sensor nodes," Computer Communications, vol. 26, no. 11, pp. 1131-1144, 2003.

[24] C. Man-Sang and J. Dayou, "Optimization of piezoelectric energy harvesting system using split-width method," in Proceedings of the 3rd CUTSE International Conference, Miri, Malaysia, November 2011.

[25] S. Kavitha, R. J. Daniel, and K. Sumangala, "A simple analytical design approach based on computer aided analysis of bulk micromachined piezoresistive MEMS accelerometer for concrete SHM applications," Measurement, vol. 46, no. 9, pp. 3372-3388, 2013.

[26] S. Kavitha, R. J. Daniel, and K. Sumangala, "Design and analysis of bulk micromachined piezoresistive MEMS accelerometer for concrete SHM applications," Sensors \& Transducers Journal, vol. 144, no. 9, pp. 62-75, 2012.

[27] S. Kavitha, R. J. Daniel, and K. Sumangala, "High performance MEMS accelerometers for concrete SHM applications and comparison with COTS accelerometers," Mechanical Systems and Signal Processing, vol. 66-67, pp. 410-424, 2016.

[28] X. Zhao, Z. Shang, G. Luo, and L. Deng, "A vibration energy harvester using AlN piezoelectric cantilever array," Microelectronic Engineering, vol. 142, pp. 47-51, 2015.

[29] P. Wang and H. Du, "A ZnO thin film based piezoelectric vibration energy harvester with two sensing elements in parallel connection," Nanotechnology and Precision Engineering, vol. 11, no. 4, pp. 309-313, 2013.

[30] R. de Reus, J. O. Gulløv, and P. R. Scheeper, "Fabrication and characterization of a piezoelectric accelerometer," Journal of Micromechanics and Microengineering, vol. 9, no. 2, pp. 123-126, 1999.

[31] A. Iula, N. Lamberti, and M. Pappalardo, "Analysis and experimental evaluation of a new planar piezoelectric accelerometer," IEEE/ASME Transactions on Mechatronics, vol. 4, no. 2, pp. 207212, 1999.

[32] M. J. Vellekoop, C. C. O. Visser, P. M. Sarro, and A. Venema, "Compatibility of zinc oxide with silicon IC processing," Sensors and Actuators: A. Physical, vol. 23, no. 1-3, pp. 1027-1030, 1990.

[33] T. Xu, G. Wu, G. Zhang, and Y. Hao, "The compatibility of $\mathrm{ZnO}$ piezoelectric film with micromachining process," Sensors and Actuators, A: Physical, vol. 104, no. 1, pp. 61-67, 2003.

[34] L.-P. Wang, R. A. Wolf Jr., Y. Wang et al., "Design, fabrication, and measurement of high-sensitivity piezoelectric microelectromechanical systems accelerometers," Journal of Microelectromechanical Systems, vol. 12, no. 4, pp. 433-439, 2003.

[35] Y. Nemirovsky, A. Nemirovsky, P. Muralt, and N. Setter, "Design of a novel thin-film piezoelectric accelerometer," Sensors and Actuators A: Physical, vol. 56, no. 3, pp. 239-249, 1996.

[36] J. H. M. Bergmann, S. Graham, N. Howard, and A. McGregor, "Comparison of median frequency between traditional and functional sensor placements during activity monitoring," Measurement, vol. 46, no. 7, pp. 2193-2200, 2013.

[37] C. C. Hindrichsen, N. S. Almind, S. H. Brodersen, R. LouMøller, K. Hansen, and E. V. Thomsen, "Triaxial MEMS accelerometer with screen printed PZT thick film," Journal of Electroceramics, vol. 25, no. 2-4, pp. 108-115, 2010.

[38] C.-C. Lee, G. Z. Cao, and I. Y. Shen, "Effects of residual stresses on lead-zirconate-titanate (PZT) thin-film membrane microactuators," Sensors and Actuators A: Physical, vol. 159, no. 1, pp. 88-95, 2010.
[39] P. Muralt, "PZT thin films for microsensors and actuators: where do we stand?" IEEE Transactions on Ultrasonics, Ferroelectrics, and Frequency Control, vol. 47, no. 4, pp. 903-915, 2000.

[40] K. Kunz, P. Enoksson, and G. Stemme, "Highly sensitive triaxial silicon accelerometer with integrated PZT thin film detectors," Sensors and Actuators, A: Physical, vol. 92, no. 1-3, pp. 156-160, 2001.

[41] P. Luginbuhl, G.-A. Racine, P. Lerch et al., "Piezoelectric cantilever beams actuated by PZT sol-gel thin film," Sensors and Actuators, A: Physical, vol. 54, no. 1-3, pp. 530-535, 1996.

[42] S. P. Beeby, N. J. Grabham, and N. M. White, "Microprocessor implemented self-validation of thick-film PZT/silicon accelerometer," Sensors and Actuators, A: Physical, vol. 92, no. 1-3, pp. 168-174, 2001.

[43] Q. Q. Zhang, S. J. Gross, S. Tadigadapa, T. N. Jackson, F. T. Djuth, and S. Trolier-McKinstry, "Lead zirconate titanate films for d33 mode cantilever actuators," Sensors and Actuators, A: Physical, vol. 105, no. 1, pp. 91-97, 2003.

[44] H. G. Yu, L. Zou, K. Deng, R. Wolf, S. Tadigadapa, and S. TrolierMcKinstry, "Lead zirconate titanate MEMS accelerometer using interdigitated electrodes," Sensors and Actuators, A: Physical, vol. 107, no. 1, pp. 26-35, 2003.

[45] J. Xie, M. Hu, S.-F. Ling, and H. Du, "Fabrication and characterization of piezoelectric cantilever for micro transducers," Sensors and Actuators, A: Physical, vol. 126, no. 1, pp. 182-186, 2006.

[46] D. L. DeVoe and A. P. Pisano, "Surface micromachined piezoelectric accelerometers (PiXLs)," Journal of Microelectromechanical Systems, vol. 10, no. 2, pp. 180-186, 2001.

[47] C. T. Pan, Z. H. Liu, Y. C. Chen, and C. F. Liu, "Design and fabrication of flexible piezo-microgenerator by depositing $\mathrm{ZnO}$ thin films on PET substrates," Sensors and Actuators, A: Physical, vol. 159, no. 1, pp. 96-104, 2010.

[48] Y.-R. Wong, Y. Yuan, H. Du, and X. Xia, "Development of high sensitivity, large frequency bandwidth $\mathrm{ZnO}$-based accelerometers," Sensors and Actuators, A: Physical, vol. 229, pp. 23-29, 2015.

[49] K. Kim, S. Zhang, G. Salazar, and X. Jiang, "Design, fabrication and characterization of high temperature piezoelectric vibration sensor using YCOB crystals," Sensors and Actuators, A: Physical, vol. 178, pp. 40-48, 2012.

[50] R. Schulze, M. Heinrich, P. Nossol et al., "Piezoelectric P(VDFTrFE) transducers assembled with micro injection molded polymers," Sensors and Actuators, A: Physical, vol. 208, pp. 159165, 2014.

[51] J. Ryu, J.-J. Choi, B.-D. Hahn et al., " $\mathrm{Pb}(\mathrm{Zr}, \mathrm{Ti}) \mathrm{O}_{3}-$ $\mathrm{Pb}\left(\mathrm{Mn}_{1 / 3} \mathrm{Nb}_{2 / 3}\right) \mathrm{O}_{3}$ piezoelectric thick films by aerosol deposition," Materials Science and Engineering B: Solid-State Materials for Advanced Technology, vol. 170, no. 1-3, pp. 67-70, 2010.

[52] X. Gao, W.-H. Shih, and W. Y. Shih, "Induced voltage of piezoelectric unimorph cantilevers of different nonpiezoelectric/piezoelectric length ratios," Smart Materials and Structures, vol. 18, no. 12, Article ID 125018, 2009.

[53] D. Shen, J.-H. Park, J. H. Noh et al., "Micromachined PZT cantilever based on SOI structure for low frequency vibration energy harvesting," Sensors and Actuators, A: Physical, vol. 154, no. 1, pp. 103-108, 2009.

[54] A. T. Mineto, M. P. de Souza Braun, H. A. Navarro, and P. Sérgio Varoto, "Modeling of a cantilever beam for piezoelectric energy harvesting," in Proceedings of the 9th Brazilian conference on Dynamics, Control and Their Applications (DINCON '10), Serra Negra, Brazil, 2010. 
[55] M. Ferrari, V. Ferrari, M. Guizzetti, D. Marioli, and A. Taroni, "Piezoelectric multifrequency energy converter for power harvesting in autonomous microsystems," Sensors and Actuators, A: Physical, vol. 142, no. 1, pp. 329-335, 2008.

[56] A. M. Hedayetullah, Analysis of piezoelectric energy harvesting for bridge health monitoring systems [Master of Science in Computational Mechanics thesis], Swansea University, 2010.

[57] T. Hehn and Y. Manoli, CMOS Circuits for Piezoelectric Energy Harvester Efficient Power Extraction, Interface Modeling and Loss Analysis, Springer, Berlin, Germany, 2015.

[58] G. De Giuseppe, A. Centuori, and A. Malvasi, "Energy harvesting using piezoelectric cantilever: improved SPICE model, simulations and measurements Equivalent," in Proceedings of the 20th IMEKO TC4 International Symposium and 18th International Workshop on ADC Modelling and Testing Research on Electric and Electronic Measurement for the Economic Upturn, Benevento, Italy, September 2014. 

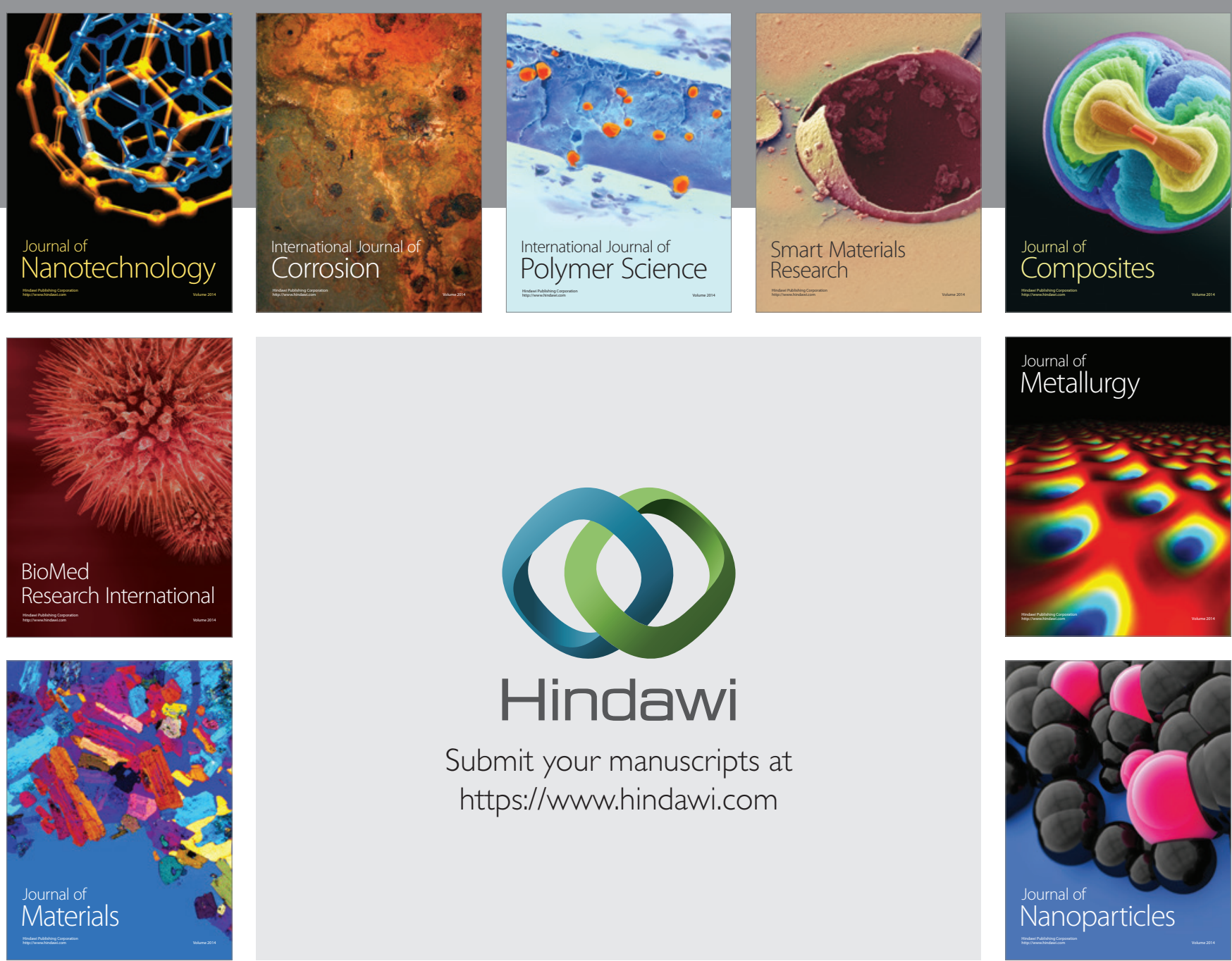

\section{Hindawi}

Submit your manuscripts at

https://www.hindawi.com

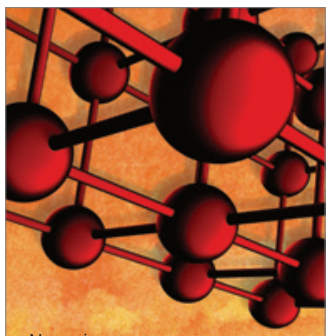

Materials Science and Engineering
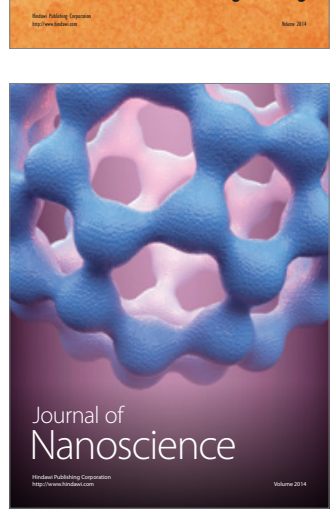
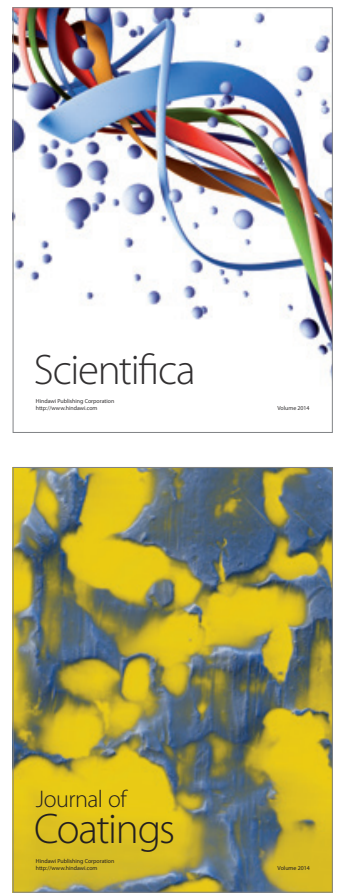
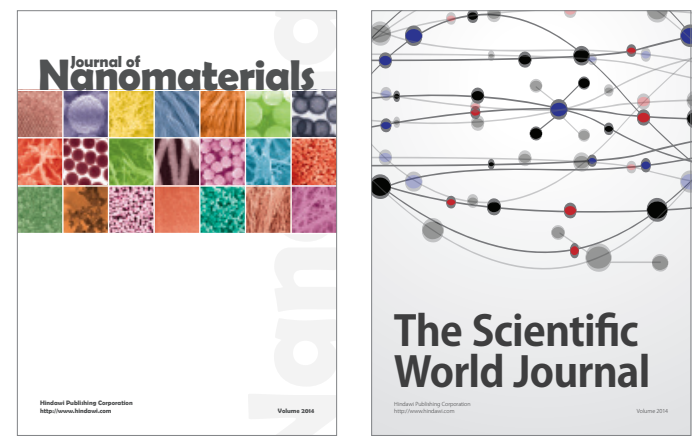

The Scientific World Journal
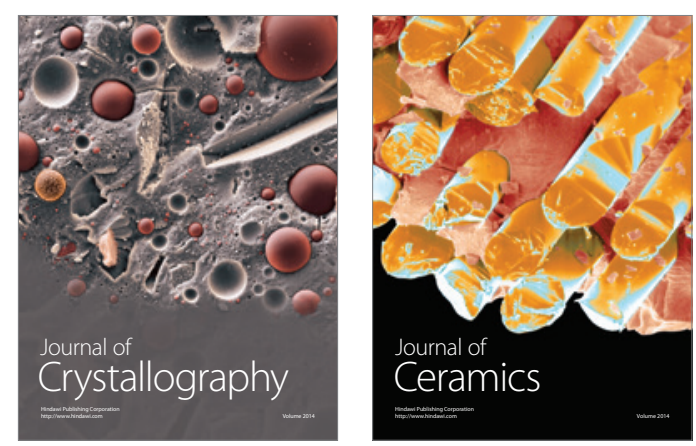
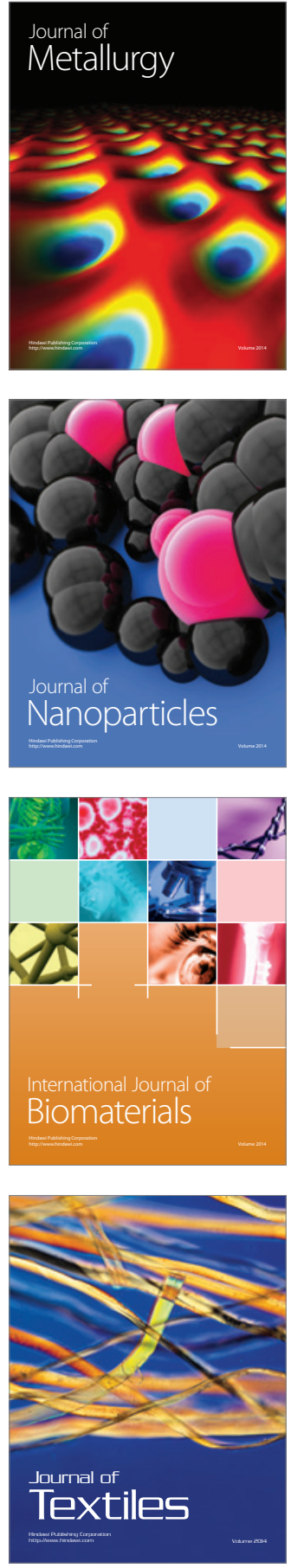